\title{
A new Middle Devonian dipnoan from Morocco: structure and histology of the dental plates
}

\author{
K.S.W. Campbell ${ }^{1}$, R.E. Barwick ${ }^{1}$, B.D.E. Chatterton ${ }^{2}$ and T.R. Smithson ${ }^{3}$ \\ ${ }^{\prime}$ Geology Dept, Australian National University, Canberra, 0200, Australia \\ ${ }^{2}$ Dept. Earth and Atmospheric Sciences, University of Alberta, Edmonton, Alberta, Canada, T6G 2E3 \\ ${ }^{3}$ Aylesbury College, Oxford Rd., Aylesbury, Bucks., HP21 8PD UK
}

\begin{abstract}
A new genus and species of dipnorhynchid dipnoan, Dipnotuberculus gnathodus gen. et sp. nov., has been found in the Givetian of Ma'der Basin of South Morocco (Presaharian Anti-Atlas). Three palates and two mandibles are available at present, all of them incomplete. No dermal roofing bones are available to us, though the dermal skeleton of the mandible is available. Large tuberosities on the palate and the mandible, the marginal addition of small blisters around the dental plates, the growth of tuberosities away from the plate margins, the elongate surangular, the large anterior pit with openings down into the Meckelian space, the great median length of the mandible, and the modification of dental surface by thick dentine and massive bone underlying it, demonstrate that the specimens have affinities with the Emsian genus Dipnorhynchus. Dipnorhynchus is one of the most primitive genera known, but some features of Dipnotuberculus indicate that many changes have taken place between the Emsian and the Givetian within the Dipnorhynchidae. Relationships with other Devonian genera are outlined.
\end{abstract}

\section{INTRODUCTION}

The material on which this description is based has a collection history. In 1990, a dipnoan palate from Morocco was purchased by the Parc de Miguasha in Quebec, Canada, from a German dealer. The dipnoan was given to Richard Cloutier to study. Another limestone block contained an arthrodire is now housed in the National Museum in Paris (MHNM 02-178), and now identified as Madiera falipouli Lelièvre (1995). From this the conodonts indicative of early to middle Givetian age were found. In 1994, Dr Roberta Paton of the National Scottish Museum, in Edinburgh, showed Smithson a dipnoan mandible that had been obtained from a rock shop in Lyme Regis, Dorset, U.K. Recognising its similarity to the Australian Dipnorhynchus, Smithson sent photographs to Campbell and Barwick in Canberra. Because of the difficulties encountered by some workers who worked on bought material, it was agreed that other palaeontologists who worked in North Africa should be contacted to enquire if they had similar material. Hence Dr Paton contacted Dr Lelièvre of the Laboratoire de Paléontologie in Paris; he was aware of the specimen from Miguasha, and had prepared the other specimen with Madiera falipouli Leliévre.

Subsequently, Chatterton and a postgraduate student who were working on Devonian trilobites from Morocco, bought a second palate, and obtained an incomplete mandible from an English dealer in fossils. The dealer had been alerted by Chatterton to the possibility of finding large dipnoans in association with the possible food items such as large invertebrates, mainly because he had found Dipnorhynchus in association with the brachiopods Spinella and Protochonetes and several nautiloids in New South Wales. Such species had been found in association with the holotype and other specimens of D. sussmilchi, as well as specimens of $D$. kurikae. Both the palate and the mandible were from Djbel Issoumour near the summit of escarpment within or just below the large Phacops (Drotops) megalomanicus phacopid bed, near Alnif, Moroccan Sahara (see Figure 1). Both of these lungfish specimens were sent to Campbell and Barwick for study, Chatterton already being familiar with the Emsian dipnoans from New South Wales. These two specimens are now in the University of Alberta Paleontological Collections UALVP 44559, 44560. Thus there are three incomplete palates, an incomplete mandible and a much more complete mandible, making up the complete collection. Lelièvre (pers. comm.) has indicated that some specimens also come from Djbel Merakib, also in the Ma'der Basin.

In the present paper we are describing the mandible in the National Museum of Scotland in Edinburgh, and the two other specimens in the University of Alberta Collection. We believe that Cloutier and Lelièvre will describe the Miguasha specimen and the new palate which is in Lelièvre's 
Collection at the Muséum National d'Histoire Naturelle in Paris, plus any comments they have on the other material.

\section{MATERIALS AND METHODS}

The specimens were preserved in limestone and were etched with acetic acid. The bones were

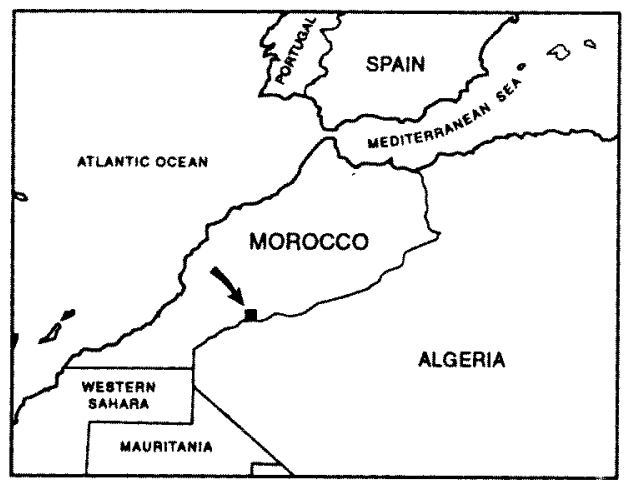

\section{Djebel Issoumour}

$$
\begin{aligned}
& 30^{\circ} 02^{\prime} 00.8^{\prime \prime} \\
& 05^{\circ} 00^{\prime} 36.0^{\prime \prime}
\end{aligned}
$$

Radiaspis/echinoderms

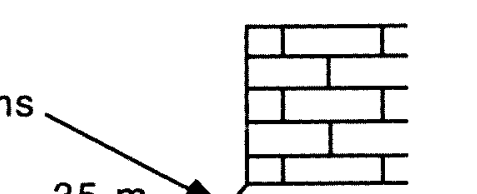

Phacops (Drotops) armatus

$35 \mathrm{~m}$

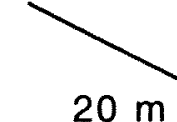

Phacops (Drotops) megalomanicus

Lungfish horizon

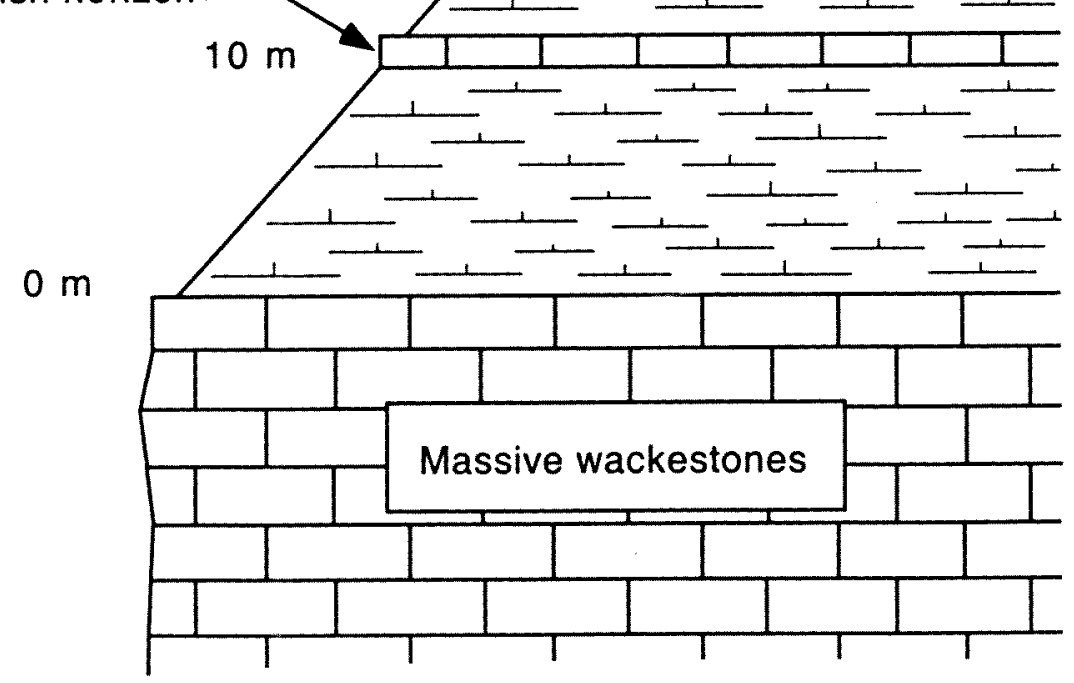

Figure 1 a. Map showing Morocco and the approximate position of the fossil locality indicated with an arrow. b. Diagram of a section through part of the Bou-Dib Formation measured by Kevin Brett in 1998. The three horizons containing trilobites are quarried for sale. Consequently, large amounts of rock are removed from these horizons, and are examined with care by local professional fossil collectors. Some of the specimens of the lungfish described here were reported to have come from the horizon containing Phacops (Drotops) megalomanicus Struve, on Djbel Issoumour, and were collected from somewhere close to this location. Latitude and longitude obtained from a hand held GPS unit, reportedly accurate to ca. 100 metres. 
stabilised with MOWITAL, a solution which penetrates the bone and binds it together. Photographs were made by covering the surface with ammonium chloride before making the negatives.

Thin sections were cut using a thin saw blade, and mounting the surface on a glass slide. The cut surface was polished on a diamond wheel to remove the coarse scratches, and then mounted for SEM examination. The SEM work was done on a Cambridge machine, and photographs were made from the negatives. EDAX analysis was done on the SEM while the specimen was mounted for making negatives.

\section{STRATIGRAPHY}

The only published information on the ages of the specimens was Lelièvre's comment that the specimen of Madiera falipouli contains conodonts of early and middle Givetian age. A copy of the section at Djbel Issoumour prepared by Chatterton and his student, Kevin Brett, is included as Figure 1.

The phacopid bed is in the Bou Díb Formation (of Hollard 1974), and contains the conodonts Polygnathus varca, Polygnathus foliata and Polygnathus linguiformis linguiformis, indicative of an early to middle Givetian age. Middle Devonian conodonts from the nearby Ma'der region have been described by Bultynck (1985) and by Bensaid et al. (1985).

The Alberta mandible contained a large amount of matrix which has been processed for conodonts by Dr Robert Nicholl, and identified by Chatterton. The following species have been recorded: Belodella devonica (Stauffer), Belodella resima (Phillip), Belodella triangularis (Stauffer), Icriodus brevis Stauffer, Icriodus obliquimarginatus Bischoff and Ziegler, Neopanderodus aequabilis Telford, Polygnathus varcus Stauffer, Polygnathus linguiformis linguiformis Hinde, Polygnathus xylus ensensis Ziegler and Clapper. These taxa indicate that the mandible came from the lower varcus Subzone, of early to middle Givetian age. This is consistent with the age given by Lelièvre for the Madiera falipouli placoderm. Thus three of the lungfish are from rocks of the same age. The present authors do not have conodonts from the specimen in the National Museum of Scotland, but its matrix is of the same kind as has been observed on the other specimens. We have no evidence of the age of the specimen in the Miguasha Museum.

\section{SYSTEMATICS} Suborder Dipnorhynchina Campbell \& Barwick
1990

\section{Family Dipnorhynchidae Berg 1940}

Genus Dipnotuberculus gen. nov.

\section{Type species}

Dipnotuberculus gnathodus sp. nov. from the Middle Devonian (Givetian) of the Ma'der Basin, Morocco.

\section{Diagnosis}

Large specimens even for the Dipnorhynchina; width unusually large for an animal with this palatal length; palate formed of a single plate and shows no sign of a median suture on either its ventral or the dorsal surfaces; margin of palate with a raised rim along its posterolateral edge; anteriorly the edge carries two pairs of large isolated tuberosities on each side; a median tuberosity shows evidence of the fusion of the anterior unit on each side. Large flattened tuberosity on each side medial to the posterior marginal ridge, and two or more smaller tuberosities between these and the anterior tuberosity. Midline of palate with a single row of three or four flattened tuberosities, the largest one posteriorly and the more anterior ones much lower and shorter. Dorsal surface of the palate covered with a thin periosteal layer over coarse vesicular bone. No periosteal bone stands vertically to form an outer layer for the braincase, as it does in Dipnorhynchus.

Four infradentary bones present, but their edges are only clear where they intersect the posterior edge of the mandible; surangular long, extending almost to the dentary anteriorly; a shallow groove on the external surface against the infradentaries, separates off the dentary; anterior furrow well developed, but not restricted laterally; foramina in the floor of the anterior furrow leading down into the abundant symphyseal tubules. Adductor fossa large with its anterior edge formed by a contact between the surangular and the prearticular. Prearticulars join medially without a suture; three well-rounded, elongated, lateral tuberosities on the prearticular, inner surface consists of a raised rounded ridge, subdivided irregularly by narrow transverse grooves into three or four tuberosities; deep depressions with a coarse surface on the inner face of the lateral tubercles occluded with the tuberosities of the palate.

Tuberosities and the dental surface formed of a thick layer of dark-coloured dentine joined ventrally to open-textured light coloured bone; large resorption openings in the base of the dentine into which new dentine grew during ontogeny.

\section{Remarks}

Because they have been independently collected by several dealers, it is possible that all the specimens to hand are not contemporaneous, and 
may not be members of the one species. Despite this, studies of the conodonts from two specimens and the knowledge that two others were from within or below the phacopid bed, demonstrate that they were also of approximately the same age. In addition, the specimens have so much in common that it is possible to write a diagnosis including all the features listed above. The genus is so distinctive that it should be easily recognised in any other areas where it appears.

The above diagnosis is extensive because it contains new data on a group not previously known from the Northern African Devonian, and comparison is made with the other members of the dipnoans from Australia. All the distinctive features are listed so that comparison with other genera will be obvious.

\section{Etymology}

dipno = referring to the group Dipnoi.

tuberculus $=$ refers to the tuberculate dentition.

\section{Dipnotuberculus gnathodus sp. nov.}

\section{Holotype \\ UALVP 44559 (mandible) University of Alberta.}

\section{Location and Horizon}

Djebel Issoumour, Moroccan Sahara. From the Phacopid Bed, early to middle Givetian. The material available for the present study consists of a palate, an incomplete mandible and the dental plates of a second mandible.

\section{Paratypes}

UALVP 44560 and NSM 1993.57.1.

\section{Diagnosis}

As for genus.

\section{Etymology \\ gnathodus $=$ refers to the jaw.}

\section{Description}

\section{Palate}

The palate has a broad anterior angle of about $75^{\circ}$ (Figures $3 a, b$ ). The adult structure consists of a single entity which has no median suture. Anteriorly the lateral margins converge to a point without any excavation for the attachment of the dermopalatines. This is quite unlike Dipnorhynchus in which a gap occurs in the anterior edge of the pterygoids, into which the dermopalatines fit. Of course, the dermopalatines are attached to the pterygoids in that genus. In Dipnotuberculus there is no evidence that the dermopalatines have been incorporated into the main bony structure. We can only conclude that they had become loose and had taken up a free position as they did in Chirodipterus, Holodipterus and other Middle and Late Devonian dipnoans. We note also that in a recent paper by Krupina and Reisz (1999), a growth series of the Late Devonian Andreyevichthys shows that a pair of small plates grew anteriorly to the pterygoids. In Chirodipterus and most other Late Devonian genera, the dermopalatines do not attach to the pterygoids but are not so far forward as those of Andreyevichthys; note that a small median plate, which is also free of the pterygoids, is not so far forward as in Andreyevichthys. In these genera we have an intermediate position between Dipnorhynchus and Andreyevichthys. Although our only example of Dipnotuberculus has neither a dermopalatine nor a median plate, we conclude that they would have features similar to those of Chirodipterus.

At the anterior end of the pterygoids is a large rounded bony mass forming a median tuberosity (Figure 3a). It shows slight evidence of having been a divided entity originally, but wear has destroyed most of the junction between the two elements. Support for the view that it was a double structure is given by the mandible in which there is a median tuberosity with a wear pit on each side (Figure 5a). Posterior to this, the margins of the palate carry two large rounded tuberosities bounded by strong furrows which pass medially beyond them. The posterior furrow is missing on the right side of the specimen. The posterior lateral edge of the palate is formed of a rounded ridge (Figure 3a). The posterior margins are incompletely preserved.

Medial to the posterior lateral ridge on the palate is a shallow groove separating off a broad flattened bony platform-like tubercle. The internal edge of the platform is steeply inclined and is bounded internally by a shallow furrow, which passes around the posterior edge of the platform becoming weaker laterally. Anteriorly the platform is bordered by a shallow furrow within which is a narrow, shallow, and sharp-edged groove. Anterior to the platform are two or three slight tuberosities making a row and joining with the median anterior tuberosity. On each side of the specimen the first and second of these tuberosities are separated by thin grooves which run between the lateral tuberosities on the plate margin. As will be shown later these furrows and grooves mark the sites where new material is added to the buccal surface.

The posteromedial part of the palate is occupied by yet another flattish tuberosity, which is not as high as the tubercles lateral to it. It is bounded laterally and posteriorly by shallow furrows, but anteriorly its edge is indefinite. Anterior to this is a low rounded ridge running almost to the anterior tuberosity. This may have carried up to three 


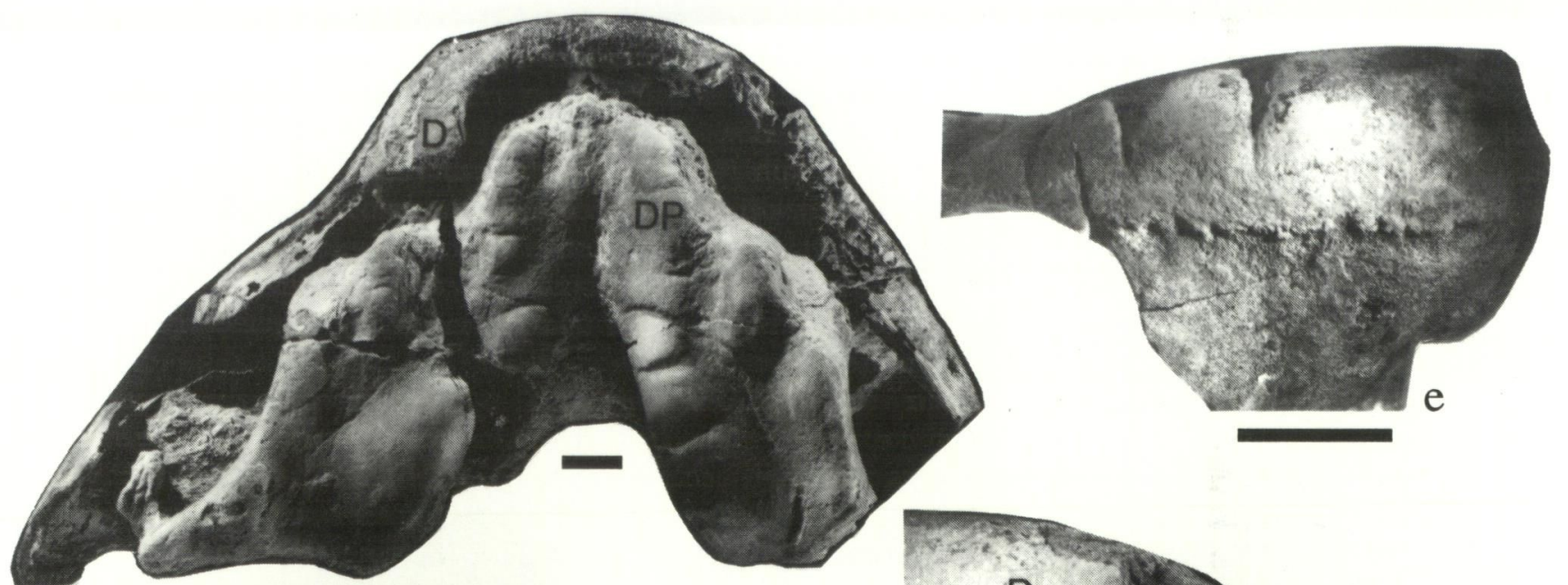

a
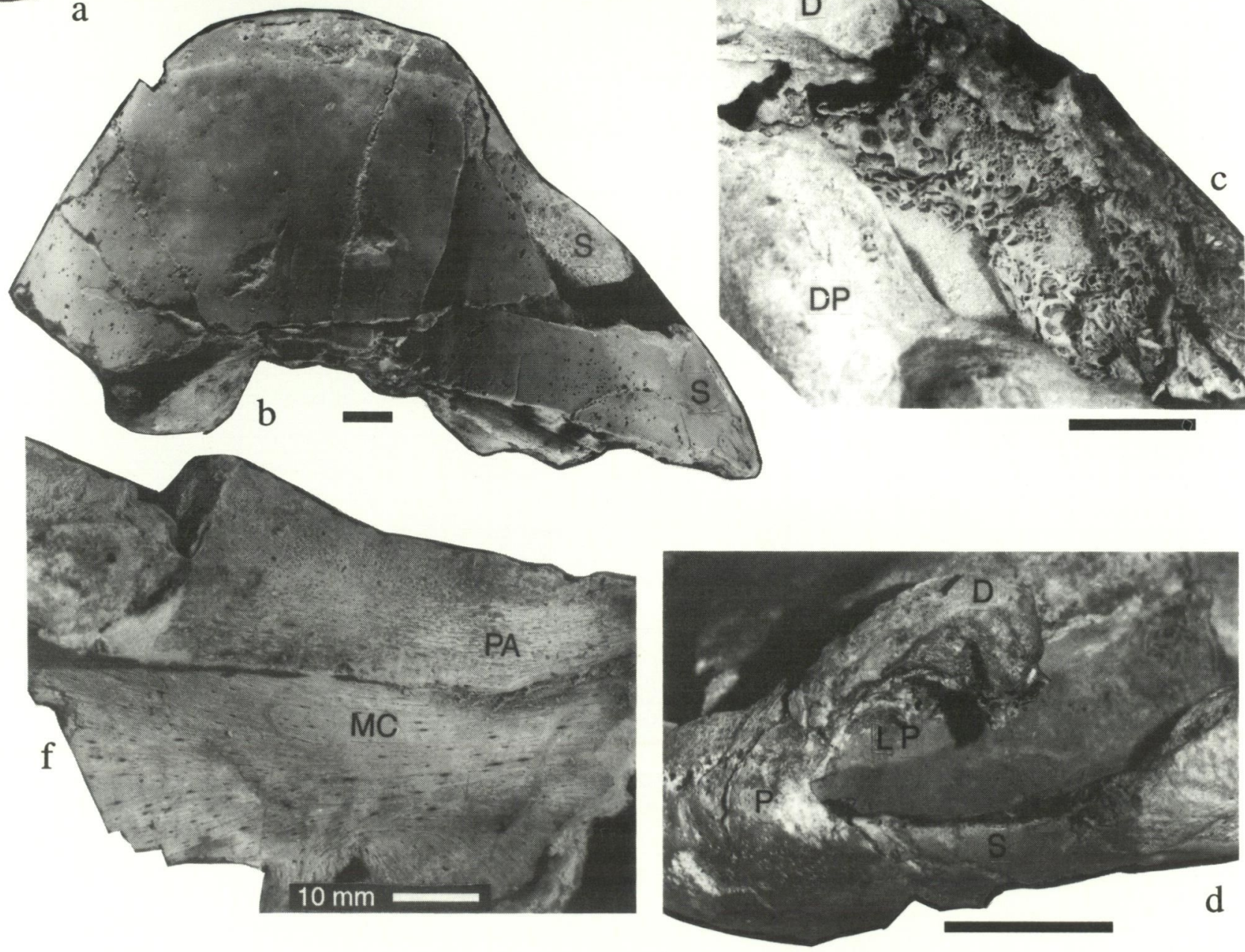

Figure 2 Dipnotuberculus gnathodus gen. et sp. nov. All illustrations are of the specimen NSM 1993.57.1. (a-b). Dorsal and ventral view of the specimen which was subsequently broken (D dentary; DP dental plate; S surangular). (c). View of the anterolateral corner of the broken specimen showing the complex tubules between the external dermal bones. (d). Anterolateral view of left corner showing the large pores (P) in the dentary (D), the labial pit still containing sediment (LP), and the cosmine of the surangular (S). (e). Lingual view of right dental plate showing the irregular edge of the dentine on the bone of the prearticular. (f). Internal view of the adductor space with the broken prearticular (PA) lying on the ossified Meckel's Cartilage (MC).

tuberosities, but they are very poorly defined. The furrow bounding this median group of tuberosities, continues forward as a shallowing structure almost to the posterior end of the median anterior tuberosity.
The posterior end of the palate is not preserved on our specimen, but on the right side (Figure 3c) the flattish dorsal surface approaches close enough to the buccal surface to show that there was only a thin surface of bone between them. Also on the right side 


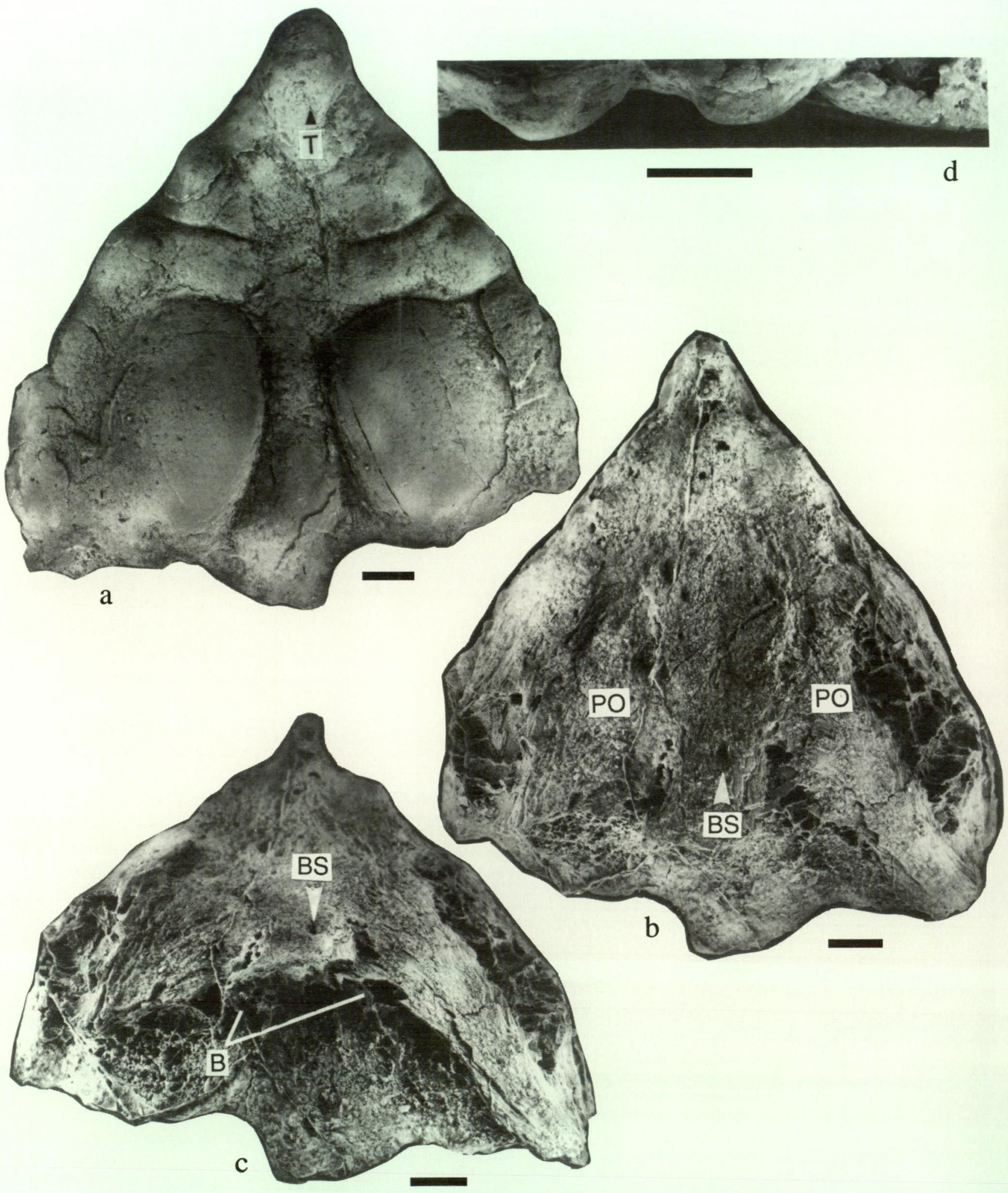

Figure 3 The palate UALVP 44560. (a-b). Ventral and dorsal views of the palate. $\mathrm{T}$ is the median tuberosity. In (b) note the coarse bone texture where the periosteal layer has been removed, the striated surface of the periosteal layer (PO), and the raised medial surface with the foramen for the buccohypophyseal stalk (BS). (c). Posterodorsal view of same showing the raised medial region separated from the buccal surface by coarse vascular bone (B). (d). Lateral view of the left side of the palate showing the blisters along the edge.

the lateral ridge on the buccal surface is reduced as it approaches its posterior end and turns medially. From both these features we conclude that the posterior face of the skull had no vertical ossified ridge as found in Dipnorhynchus. Presumably in Dipnotuberculus the posterior face supporting the otic region, and separating the adductor chamber from the gill chamber, was made of cartilage. 
The lateral margins of the palate are somewhat worn. The hard material along the edges is thin, and lies on a thick layer of bone which does not reach the outer edge of the hard surface. In places where the outer edge of the hard surface is preserved, especially along the surface of the tubercles, including the anterior tubercle, the pattern of deposition of the tissue is preserved. As shown on Figure $3 \mathrm{~d}$ the additions of new tissue are flat blisters of dental tissue attached to the bony substrate. Along the more posterior ridge, the blisters are smaller. The surface of these structures show the same features as the surface of the tuberosities.

The visceral (dorsal) surface of the palate is poorly preserved, and its surface is deeply eroded posteriorly (Figure $3 b, c)$. This exposes the very open meshwork of tissue forming the dorsal surface of the pterygoid bone, which overlies the denser vesicular layers close to the buccal surface. The dorsal surface of the pterygoid is covered with a thin layer of periosteal bone which makes a roughened dorsal surface (Figure $3 b, c)$. Medially there is no bony connection between the braincase and this layer except posteriorly. This implies that the braincase did not sit directly on the dorsal surface of the palate, but presumably it was oriented above it by a layer of cartilage. This is in contrast with Dipnorhynchus in which the periosteal layer continues up the side of the braincase leaving a strong coarse bony layer along the palate after weathering (Thomson and Campbell, 1971, figure 73; Campbell and Barwick, 1985, figure 5b,c).

Anteriorly, the specimen shows a thick bony boss dorsal to the most anterior palatal tuberosities (Figure 3c). Details of the surface of this dorsal boss were lost by weathering; therefore it is not possible to identify the parts of the anterior end of the braincase, but there is little doubt that they were connected in some way in life. Its anterior end of the boss must have supported the base of the internasal septum as it does in dipnorhynchids.

The dorsal surface of the posterior third of the pterygoids is difficult to interpret. The bone must have been particularly coarsely grained and thick, and much of it has been eroded away during preservation. The lateral margins have a high rounded ridge, best preserved on the left side (Figures $3 b, c$ ), and these presumably surfaced in a weak dorsal palatal process. This area is weathered on both sides of the specimen, but the bony trabeculae preserved suggest that such a palatal process was present. The contours of the surrounding bone indicate that the process was unlikely to be as strong as the ones in dipnorhynchids. Behind that the surface drops away to what must have been the quadrate surface. As mentioned above, no strong ossified wall supporting the otic region of the braincase is preserved. This region must originally have been made of cartilage.

The postero-central part of the visceral surface forms a high ridge (Figure 3c) which is smooth crested and is supported by very coarsely vesicular underlying bone. The median part contains a well rounded perforation for the buccohypophyseal stalk (Figure 3b), but the stalk does not continue down to the palate. We note that in Dipnorhynchus, we have a single specimen in which no buccohypophyseal opening is present, even though all other specimens have such a structure. During periods of regrowth, the surface of the palate was covered by hard tissue and the buccohypophyseal opening was at least temporarily covered.

In neither ventral, dorsal nor posterior views does the bone structure show evidence of sutures between what could be regarded as a boundary between the parasphenoidal bone and the pterygoids. So far as we are aware the parasphenoid boundary in this region remains unknown. This matter will be dealt with separately in the latter part of the paper. At this point we note that sections across a well preserved palate of Dipnorhynchus kurikae show no evidence of any boundaries of a parasphenoid on the buccal surface, and new specimens of D. sussmilchi (Campbell et al. 2000) confirm this view. The dorsal view of another specimen of $D$. kurikae shows an edge which we presume is the margin of the parasphenoid extending forwards around the anterior edge of the buccohypophyseal opening. In Dipnorhynchus, therefore, the parasphenoid does not appear between the dental plates on the palatal surface, but probably continues forward on the visceral surface to the buccohypophyseal canal.

In Dipnorhynchus the antorbital wall and the postnasal process are large and heavily ossified, forming a distinct feature in dorsal view. We note that there is no evidence of such a feature in Dipnotuberculus, even though our specimen is relatively well preserved in these areas. Presumably the posterior wall of the nasal cavity and the antorbital wall were made of cartilage.

\section{Mandible External Surface}

The specimen NMS 1993.57.1 is the only individual available that shows the external bones of the mandible, and it is incomplete (Figure $2 a-c$ ). Most of the external surface is covered with cosmine, though there is a break in this substance against the dentary. This specimen was broken during transport and the photographs of the entire specimen were made by Dr Lelièvre. We also have colour photographs made by Smithson. Campbell has examined the broken specimen in Edinburgh and has photographs made by Ms Susan Stevenson from the National Museum. of Scotland. Some of these are used herein. 
The mandible is wide in comparison with its length (reconstruction Figure 4), even more so than Dipnorhynchus. This accords with the width of the palate described above. The dentary is wide and short, but it does not extend posteriorly to make a sharp boundary to the anterior furrow as it does in Dipnorhynchus. As a result, the dorsolateral posterior end of the dentary is much shorter than that of the dipnorhynchids. In lateral view the posterior end of the dentary turns ventrally to make a ridge across the posterior end of the labial pit (Figure 2d). Such a structure is not present in Dipnorhynchus, in which the dentary forms a straight dorsal edge to the labial pit (Campbell and Barwick, 1985, figures 8c; 9b). The surface of the dentary carries perforations much coarser than the cosmine pits as is normal for dipnorhynchids (Figure 2d).

Posterior to the dentary on the buccal surface is an anterior furrow, much of the floor of which has been broken away. Medially in the anterior furrow is a low rounded elevation in the floor with a rounded top, which does not reach to the height of the dorsal surface of the dentary. A similar ridge is developed to a variable extent within a single species of some dipnorhynchids. The floor of the anterior furrow carries foramina which open down into the mass of symphyseal tubules (Figure 2c). The two preserved foramina are not symmetrically placed with respect to the mid-line. Other foramina must have been present, but the basal bone is not preserved in the lateral parts of the furrow.

The end of the dentary lies opposite a depression in the sides of the prearticulars lateral to the large anterior tubercle (Figure 2a). This gives the prearticular a distinctive outline. Another foramen lies in this furrow posterior to the dentary (labelled pit in Figure 4a), and this is the homologue of the foramen found in Dipnorhynchus sussmilchi; it probably opened ventrally into the Meckelian cavity.

The labial pits are not well preserved, but the broken specimen NMS 1993.57.1 shows some interesting features (Figure 2d). Ventrally the pit is surrounded by the surangular, and anteriorly and dorsally by the dentary. At least part of its inner surface is covered by the Meckelian bone. These features are common in the dipnorhynchids (Thomson and Campbell, 1971; Campbell and Barwick, 1999, 2000) .

The mandible is long medially (Figure 2a,b), but the arrangement of the prearticulars and the external dermal bones in the mid-line are different from those of Dipnorhynchus, which has a similar length. In Dipnotuberculus the join in the prearticulars carrying the dental plates drops ventrally near the posterior end of the first lateral tuberosities (Figure 2a; 5a), and the posterior floor of the lingual cavity is made up of a thin covering of prearticular bones lying on the external dermal bones (Figure $2 \mathrm{a}, \mathrm{b}$ ). In Dipnorhynchus the dental plates on the prearticulars are much longer medially, and they drop ventrally almost over the posterior end of the splenials making a sharp vertical wall posteriorly.

Four infradentaries are present, as is normal in Dipnorhynchus (Figures 2b; $4 \mathrm{~b}$ ). The sutures between the bones are restricted to the posterior part of the surface, and the anterior parts are covered with cosmine. So far as can be observed, the surangular is a narrow bone and its anterior edge runs forwards beneath the labial pit (Figure 2d), a point which can be seen on the broken specimen. It carries a large number of perforations especially towards the anterior end (Figure 2d), indicating that the lateral line canal continues this far forwards. Although its outline is not clear because of cosmine cover, the angular is probably a triangular bone which stops short of the anterior end of the surangular. It carries a large number of perforations which indicates that the lateral line runs obliquely forwards to connect with the transverse commissure, the exact position of which is not clear. The splenial is narrower than the postsplenial, which is narrower than the angular.

\section{Mandible Buccal Surface}

This is preserved on two specimens NSM 1993.57.1 and UALVP 44559. Most of the surface is covered by large prearticular plates that join medially, and have no median suture separating them (Figures 2a; 5a). The lateral walls of the lingual cavity are formed of the prearticulars which stand as a vertical wall (Figures $2 \mathrm{e} ; 5 \mathrm{a}, \mathrm{c}$ ), and the posterior end of the lingual cavity is floored by a thin layer of prearticular against the dermal bones.

The dental plates are thick and make a hard buccal surface. The histology of the plates is discussed below. The lateral margins of the prearticulars are formed of three elongate, large rounded tuberosities that stand up higher than the more mesial surface (Figures 2a; 5a). These tuberosities are not bounded by a more lateral ridge. In dorsal view the dental surface has a deep lateral embayment lying opposite the posterior projection of the dentary, another one between the first two lateral tuberosities, and a third deep embayment for the adductor pit (Figures 2a; 5a). This gives the lateral margin a distinctly waved edge. The most anterior lateral tuberosity is the largest one present, and extends forwards almost to the anterior end of the dental plate. The second tuberosity is shorter and its long axis is slightly anterolaterally directed. The third tuberosity is very much shorter, and it does not have a distinct long axis. The tubercles are separated by deep grooves, on the mesial sides of which are rough-based depressions. In addition there is a smaller cavity 

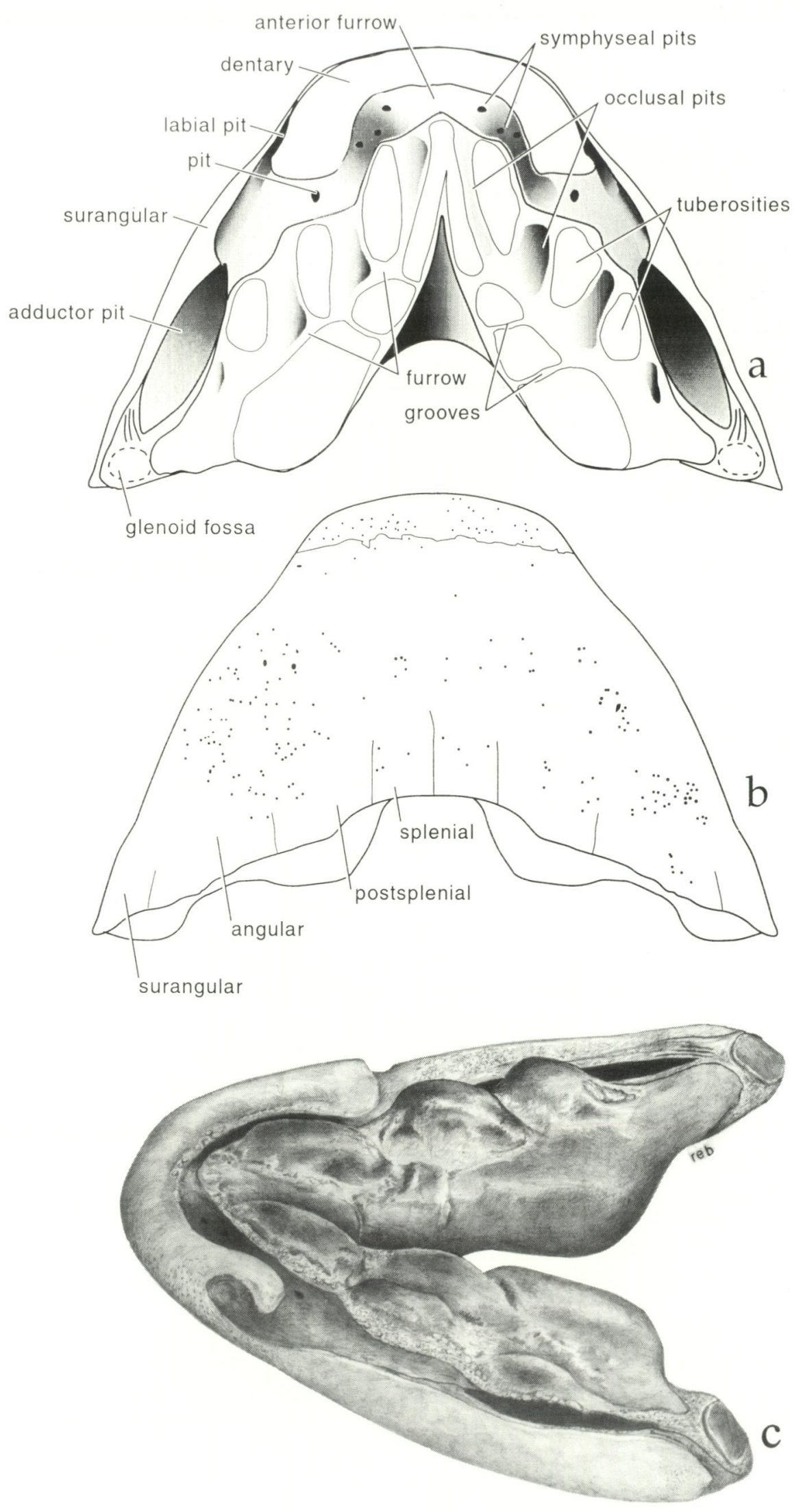

Figure 4 (a-b). Reconstructions of the dorsal and ventral outlines of NSM 1993.57.1. (a) is a composite figure which includes information from the holotype, because the surfaces of 1993.57 .1 are not clear in places. (b) is drawn symmetrically from all the data available. (c) Three dimensional structures of the specimen NSM 1957.57.1, showing the form of the lingual furrow, the anterior furrow, the adductor cavity and the position of the main dermal bones. 


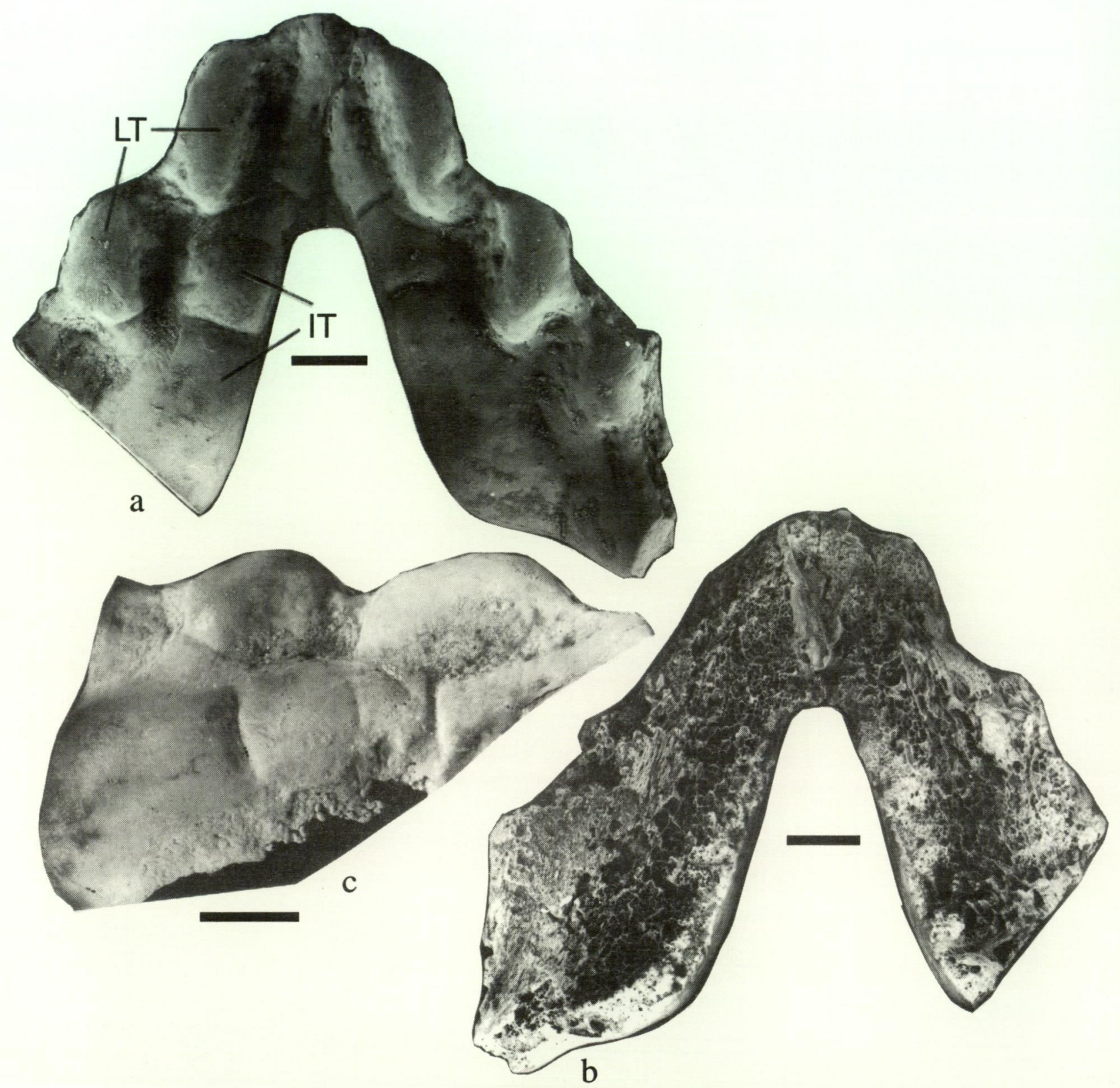

Figure 5 The holotype of Dipnotuberculus gnathodus gen. et sp. nov. UALVP 44559 (a-b). Dorsal and ventral views of an incomplete mandible. Note the large lateral tuberosities (LT), the spaces into which the palatal turberosities occlude, and the divided internal tuberosities (IT) and the gaps between them. (c). Lingual view of the dental plate and the broken tissue bordering it. Note the rough surface marking the occlusal surfaces. Compare it with Figure 2e.

behind the posterior tuberosity and adjacent to the adductor pit, into which the anterior end of the posterolateral ridge on the pterygoid must have occluded (Figures $4 \mathrm{a} ; 5 \mathrm{a}$ ). These depressions mark the surfaces where the tuberosities of the mandible occlude outside the main line of the tuberosities of the palate. The long axes of the depressions are directed anteriorly, and their surfaces are irregular, because the dentine of the plate is interrupted by the calcite of the matrix being so close to the surface (Figures $5 \mathrm{a}, \mathrm{c} ; 8 \mathrm{~b}, \mathrm{c}$ ).

Medial to the lateral tuberosities and the above depressions, is a dorsally rounded ridge which medially drops vertically down into the lingual cavity. Anteriorly this ridge extends forwards to the anterior end of the dental surface, becoming much narrower as is goes (Figure $5 \mathrm{a}$ ). The buccal surface of the ridge is broken up into large rounded tuberosities separated by thin grooves. These bands do not match on opposite sides of the one specimen. On UALVP 44559, the left side has two grooves, the posterior one being medial to the posterior end of the second lateral tuberosities. The right side has this groove further forward. Both sides have a small oblique groove running anteromedially from the posterior end of the anterior tuberosities. NMS 
1993.57.1 has a different mode of subdivision of the ridge as is shown on Figure 2a,e. These grooves are matched by the small grooves which separate the lateral tubercles from the inner rounded tubercles.

The margins of the dental plates indicate how these were modified during growth. The lateral margins show small blisters which are isolated like those of the palate (Figure $3 \mathrm{~d}$ ). The structure of the lingual surface of the dental plates is shown on UALVP 44559. These indicate that the mode of lateral growth was the same in each jaw. The structure of the dental plate margin along the lingual furrow is well shown on both mandibles. In the lingual groove of UALVP 44559, the continuous layer of dental material has a sharp boundary and below this the surface is made up of blisters of different material (Figure 5c). These blisters are separate from one another and show sharp lines at their boundaries. Some of them also lie in resorbed patches at the edge of the continuous dental surface. Clearly they are replacement structures on the inner edge. On NMS 1993.57.1 (Figure 2e), the edge is made of sharp projections, presumably the remnants of a resorption further advanced than in the other specimen.

A large adductor foramen, with a pointed anterior end and a bluntly rounded posterior end, reaches to about half the length of the mandible. Its pattern is similar to that of dipnorhynchids. Anterior to the adductor fossa, the prearticular almost certainly extended laterally to join the surangular, but in the specimen this junction was broken during preservation (Figure $4 a, c$ ).

The specimen NMS 1993.57.1 has part of the glenoid fossa preserved. By restoring the preserved edge of the surangular to the prearticular it is possible to estimate the size of the articulation (Figures $2 \mathrm{a} ; 4 \mathrm{a}, \mathrm{c}$ ). For a jaw of this size, the fossa is unusually small when compared with that of Dipnorhynchus. However we note that although we do not have a quadrate preserved, the structure of the palate also indicates that the quadrate process must have been small. This fits in with the conclusions about the fossa in the mandible.

The preglenoid area in NMS 1993.57.1 has been broken through, but it is clear that the articular was not a large bone, and the preglenoid process was not high. Part of the preglenoid process is preserved and shows a linear arrangement (Figures $2 a ; 4 a, c$ ) suggestive of muscle attachment such as occurs on Dipnorhynchus kurikae (Campbell and Barwick, 2000). This was interpreted as a muscle or ligament attachment which served to stabilise the glenoid region during biting.

\section{Mandible Internal Space}

The internal space of the mandible is largely open, but it is too poorly preserved to see the detail one sees on dipnorhynchids. The inner surface of the dentary and the anterior part of the surangular are covered with a dense mass of symphyseal tubules (Figure 2c). These extend beneath the labial pit. Some of the canals descending into these from the anterior furrow are still visible on the right side of the specimen.

On the prearticular a strong ridge lies beneath the lateral row of dental tuberosities, and this makes a sharp edge against the Meckelian bone (Figures 2f; 5b). A similar ridge occurs in Dipnorhynchus, but it is not as large as the one in Dipnotuberculus.

The left side of the broken NMS 1993.57.1 specimen shows the remains of a thick ossified Meckel's cartilage exposed along the posteromedial wall (Figure 2f). Within it there are foramina, but the region lateral to these foramina is broken away, and so the exit of the ramus mandibularis nerve $\mathrm{N}$ $\mathrm{V}$ is not preserved. The preserved foramina have not been identified. The Meckelian bone runs up inside the prearticular and shows a parallel striped surface with many foramina. This surface is comparable with the Meckelian bone lining the prearticular of Dipnorhynchus cathlesae (Campbell and Barwick, 1999, figures 11A,C;12D; 14A). The surface of the bone has the appearance of stress lines. Dipnorhynchus has multiple vertical rugae along the inner face of the Meckelian bone (Thomson and Campbell, 1971, figures 47-48), these having provided expanded surfaces for the attachment of the adductor muscles. No such rugae have been found in Dipnotuberclus.

\section{GROSS FEATURES OF THE DENTAL PLATES}

The buccal surface of the palate shows little or no sign of wear due to abrasion, except in the grooves into which the tuberosities of the palate occlude with the prearticulars. If the surface had been worn during life, many more surface features would have been removed. Not only would the marginal tuberosities have been worn down, the rounded tuberosities in the medial part of the mandible and the large flatted tubercles on the palate, would have been reduced. In addition, the grooves in the surface are clearly outlined. Consequently we conclude that the surface of the dental plates must have been remoulded during life. The question now is how could this have taken place?

In the following text we make a distinction between the broad rounded furrows separating the lateral tuberosities from one another and the lateral tuberosities from the more median tuberosities on the one hand, and the finer grooves which occasionally lie in the above depresssions, or separate tubercles as on the inner tubercular ridge on the mandible (Figure 4a). On the palate the median tuberosities are separated from the flattish tuberosites on each side by similar furrows. In addition there are much finer depressions or 

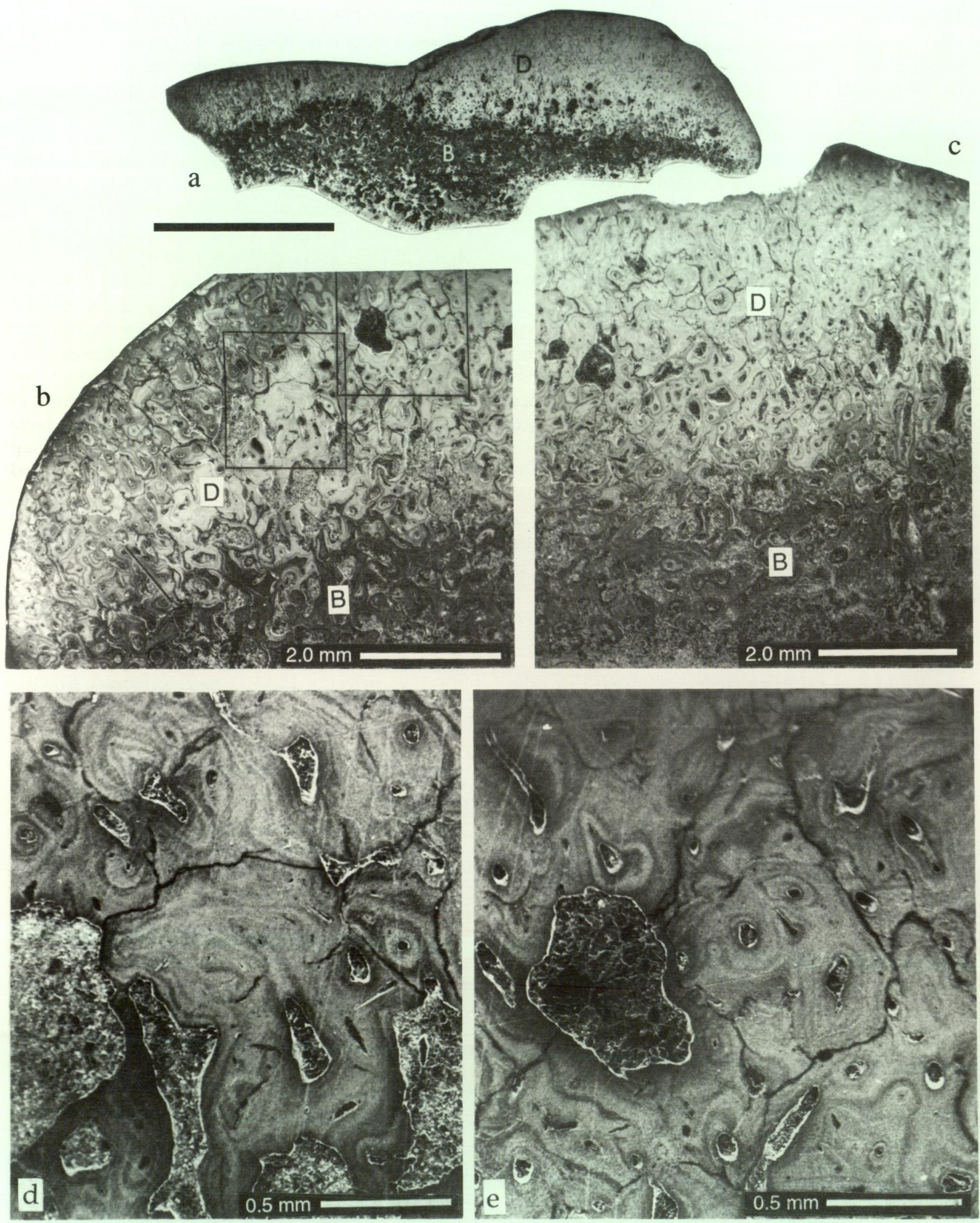

Figure 6 Vertical sections across the dental plate of the holotype, cut from the posterolateral corner of the specimen. (a). Print from a thin section with the lateral tuberosity to the left. The thick tissue to the right is the large internal tuberosity. Note the large perforations in the lower layers of the dentine and the clear boundary between the bone (B) and the dentine (D). (b-c). SEM images of a section cut parallel with the slide in (a); lingual furrow to the left, that is the section is in the reverse orientation to (a). Bone at the base marked (B) and the transition into dentine (D) dorsally, clearly marked. Note perforations in the dentine and the clusters of dentine with irregular boundaries around one or more vascular bundles. The relative positions of the two images is indicated by the small resorbed space at the upper right hand side. (d-e) SEM images of the points marked on (b) showing resorption boundaries around clusters of vascular bundles. 
grooves which in places lie in the furrows between the lateral tuberosities and extend medially to separate other tuberosities. On the mandible, similar grooves occur on the medial edges of some lateral tubercles, and they also divide the long medial tuberosity into the irregular subdivisions we observe. In the furrows the dentine is thin and the bone approaches the buccal surface, a feature that will be described below. This allows new dentine and new bone to be added at these furrows, and the dental plates are expanded. The lateral tubercles are evenly spaced and their position is determined because they have to occlude with the tubercles on the opposing jaw. Along the medial elongate tuberosity, the tubercles are not involved with precise occlusion and their position is the result of renewal processes along the ridge. New material would have been added at the grooves, and it would not have to be regularly spaced.

Periodic growth has been described from Dipnorhynchus (Campbell and Barwick, 1999, 2000). Such a phenomenon would have been difficult to explain if thick dentine was the material forming the dental plates as is found on Late Devonian and later genera. In Dipnorhynchus the pterygoids and prearticulars are thick, and part of their surface is covered with a thin sheet of dentine which varies in thickness according to its position on the dental plates. The surface of the dental plates have been modified by differential rates of growth in the underlying bone. The dentine is also modified by growth at the contact between the dentine and bone, and the shape of the dental surface is modified by periodic outgrowths of new bone via growth at the base of the superficial material.

The dark-coloured dental tissue in Dipnotuberculus, which is determined below as a distinctive form of dentine, forms a layer up to $9+\mathrm{mm}$ in thickness in the main posterior tubercle (Figure 6a), but slightly thinner in the lateral tubercles. No evidence of a thin layer of hard material occurs on the buccal surface of this dark coloured layer, but the entire layer is made up of the same material. The dentine is densest towards the buccal surface, but becomes more open ventrally towards the bone of the prearticulars. The contact between these two tissues is discussed below, but it is clear that the dentine is added to by the formation of new tissue at the junction, and by resorption and deposition of pleromic dentine in the resorbed spaces. This allows the dentine to be remodelled by internal processes. The details of this process will be discussed below.

This explains how the thickness of the dental plate material of the palate increases, but it does not explain the lateral extension of the plates and the marginal tubercles. The lateral extension of the palate could take place by additions at the posterior
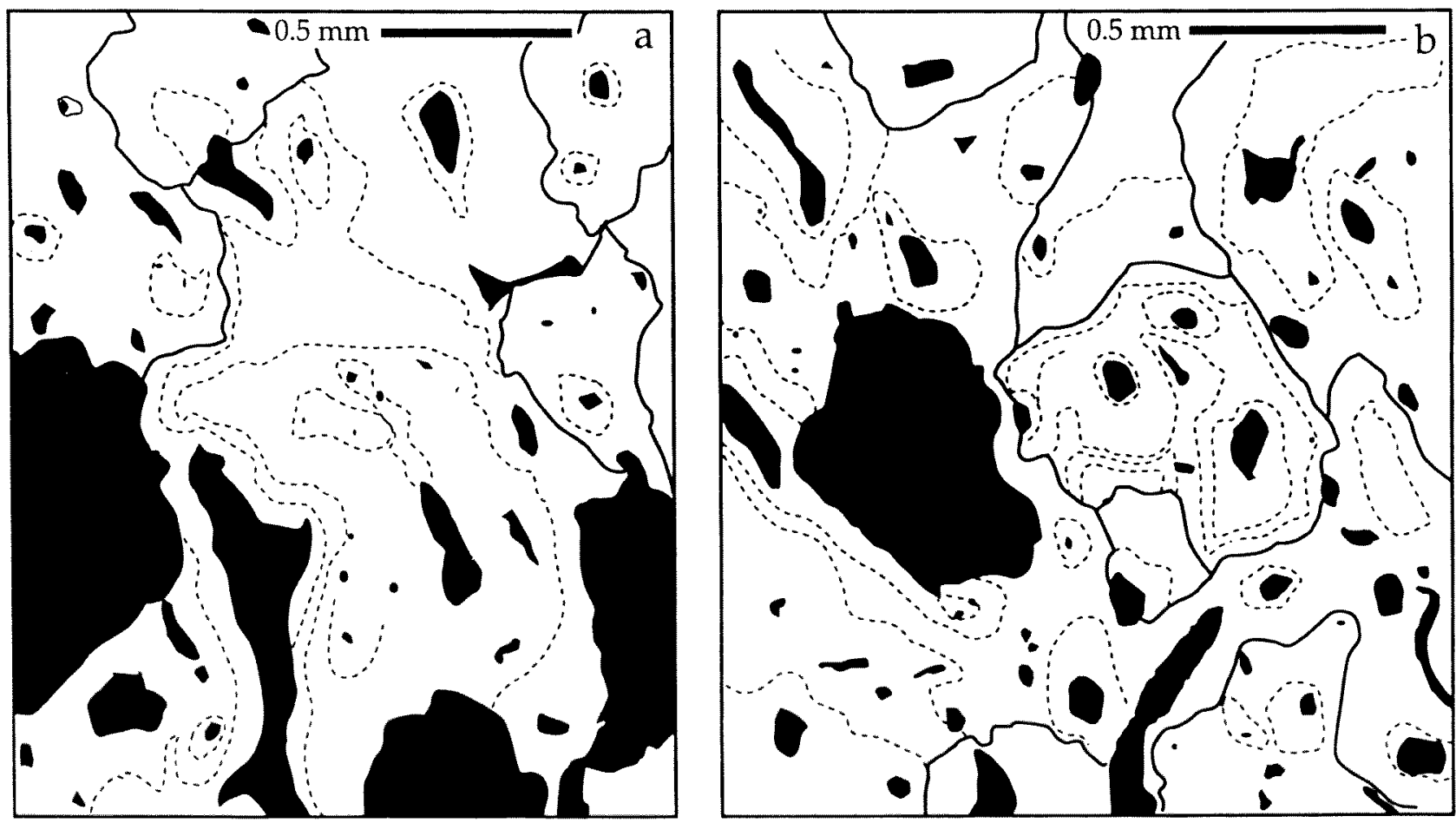

Figure 7 Drawings of parts of Figures $6 \mathrm{~d}-\mathrm{e}$, large open resorbed areas in black showing marginal resorption, cutting into the growth lines marked as dotted lines. Vascular bundles also in black and are surrounded by dotted lines showing the layers of concentric tissue. The boundaries of former resorbed areas, now occupied by pleromic dentine, are shown by dark lines. Note that the first layers extend around the whole resorbed area and successive layers are around vascular bundles. Not all layers are represented, but only those which show the main features. 
and lateral extremities. This would require no additions to the pterygoids internally such as occurred by the addition at a median suture in most later genera. We do not suggest that all addition would take place at the posterior and posterolateral edges, but this was the main area of addition. Such a suggestion is completely different from extant species of dipnoans. But we do have a specimen of Dipnorhynchus sussmilchi where the early stages of growth show the lateral margins anteriorly, and new marginal ridges were being added to them at their posterolateral ends (Campbell and Barwick, 2000).

Small scale lateral addition took place on already existing tuberosities and anterolateral margins by small rounded blisters lying on the surface. These were often obliterated by erosion during preservation, but in other places they are clearly preserved (Figure 3d). Such an arrangement has been observed in Dipnorhynchus (Thomson and Campbell, 1971, figures 79-80) and in Chirodipterus (Smith and Campbell 1987, figures 27-31). In Dipnorhynchus the composition of the blisters has not been investigated by thin sections, but they are probably made of dentine. In C. australis they are made of dentine. Lateral growth of the dental plates of both species would have occurred while the epithelium covering the plate margin permitted the plate to incorporate the blisters. Presumably a similar process occurred in Dipnotuberculus.

\section{HISTOLOGY OF THE DENTAL PLATES}

The posterior end of the left ramus of the mandible UALVP 44559 was broken across, and the details of the bone and dental plate structure could be observed (Figure 6); sections show that the bone was bored by fine organisms, probably fungae, after death. A thin section and two SEMs were prepared of this specimen, and they are figured on Figures 710. Note that all the sections examined for this work have been cut parallel with each other, and occupy the posterior end of the prearticular. We would have preferred to have sections cut in a variety of directions, but we have insufficient material to do this. Although the genus is not the most primitive of all those known from the Dipnorhynchina, it provides the best example of the histological detail

Figure 8 (a) SEM image of part of a lateral tuberosity cut so as to show the long thin openings for vascular tissues. (b-c). Two SEM images of the contact between the outer and inner tuberosities. (b) shows a boundary between the lateral and median tubercles, the bone approaching the buccal surface. (c) is close to the occlusal space for the upper tubercle and shows calcite filled cavities almost to the buccal surface.
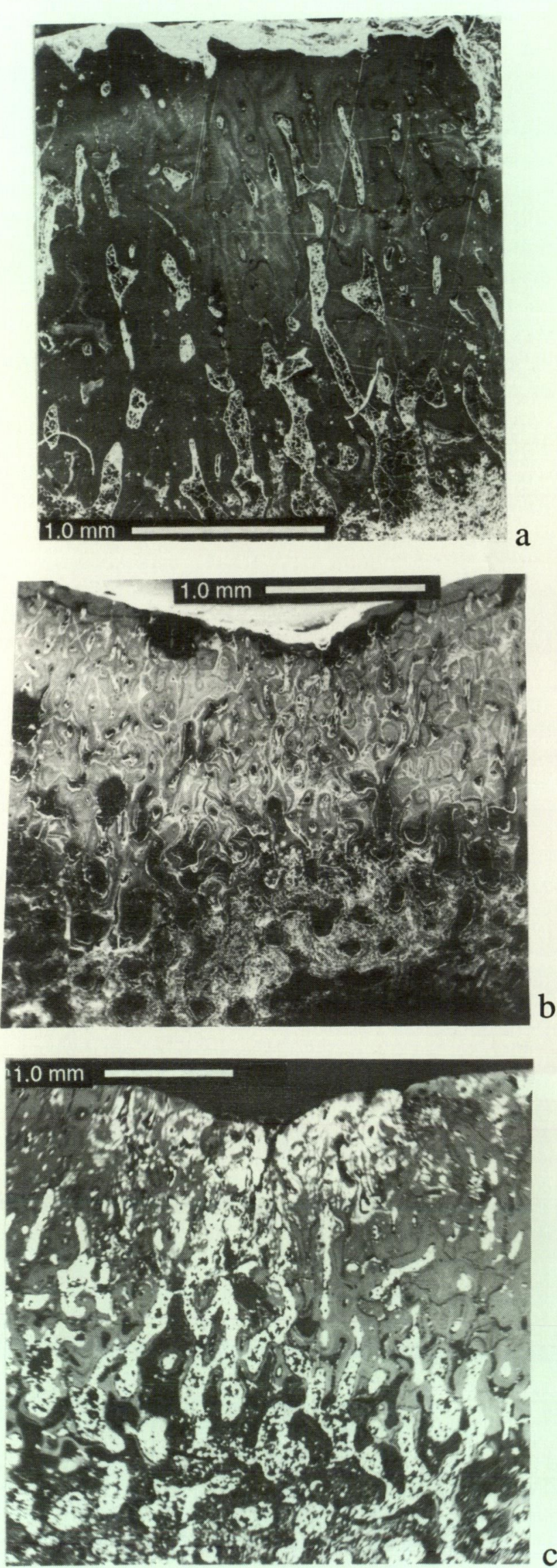

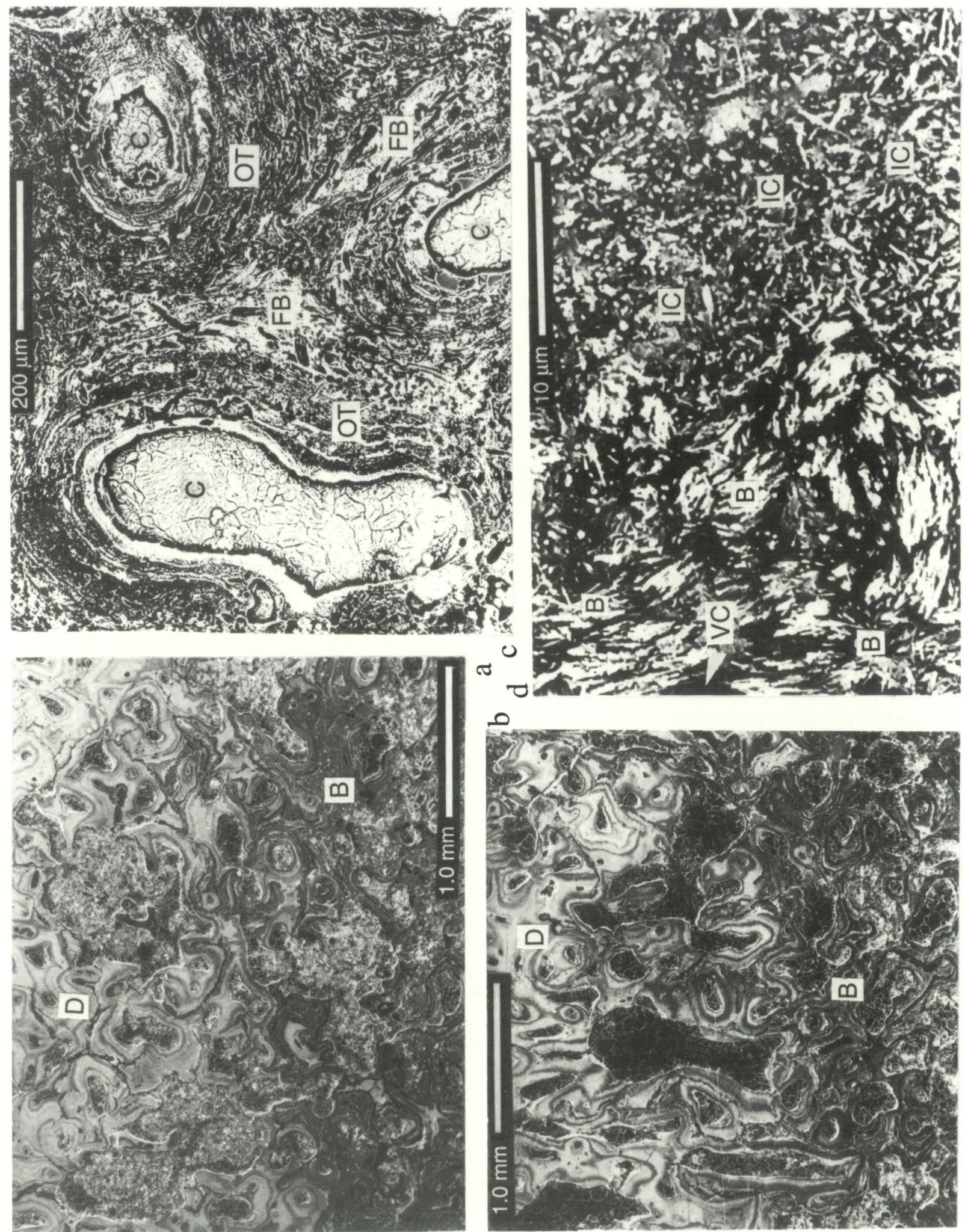

$\sigma$

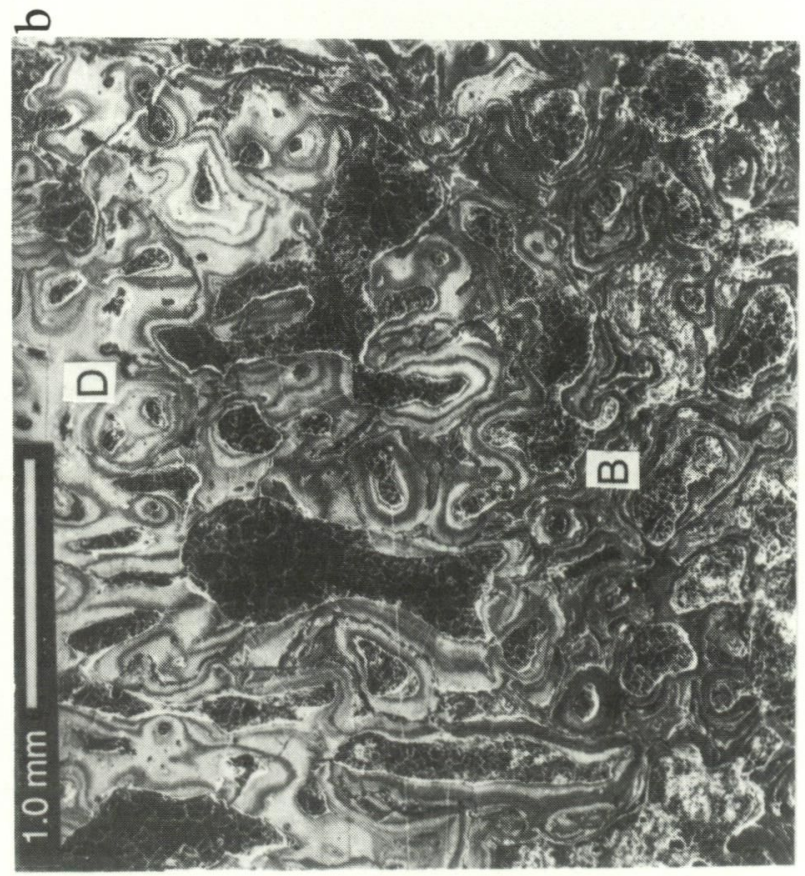

Figure 9 Landscape image of back scatter SEM images from the holotype. On all images the buccal surface is to the left side of the plate. (a). Section through the contact between the bone at the base (B) and dentine (D) at the top, with the transition between the two types of tissue shown up by the growth of later tissue around the vascular canals and sediment between the vascular units. (b). Similar section to (a) with layers of tissues well defined. (D) is dentine and (B) is bone. Reversal lines clearly shown. (c) Detail in the bony tissue with calcitefilled vascular canals (C), surrounded by concentric layers of ossified tissue (OT) and separated by layers of relatively unossified tissue containing numbers of fungal borings (FB). (d). Section through the dentine with the edge of a vascular canal (VC) on the left margin bordered by a layer of crystal bundles of apatite (B) and by irregularly arranged apatite crystals (IC). Note the elongate crystals more of less parallel with the surface and white spots representing end views of crystals. 


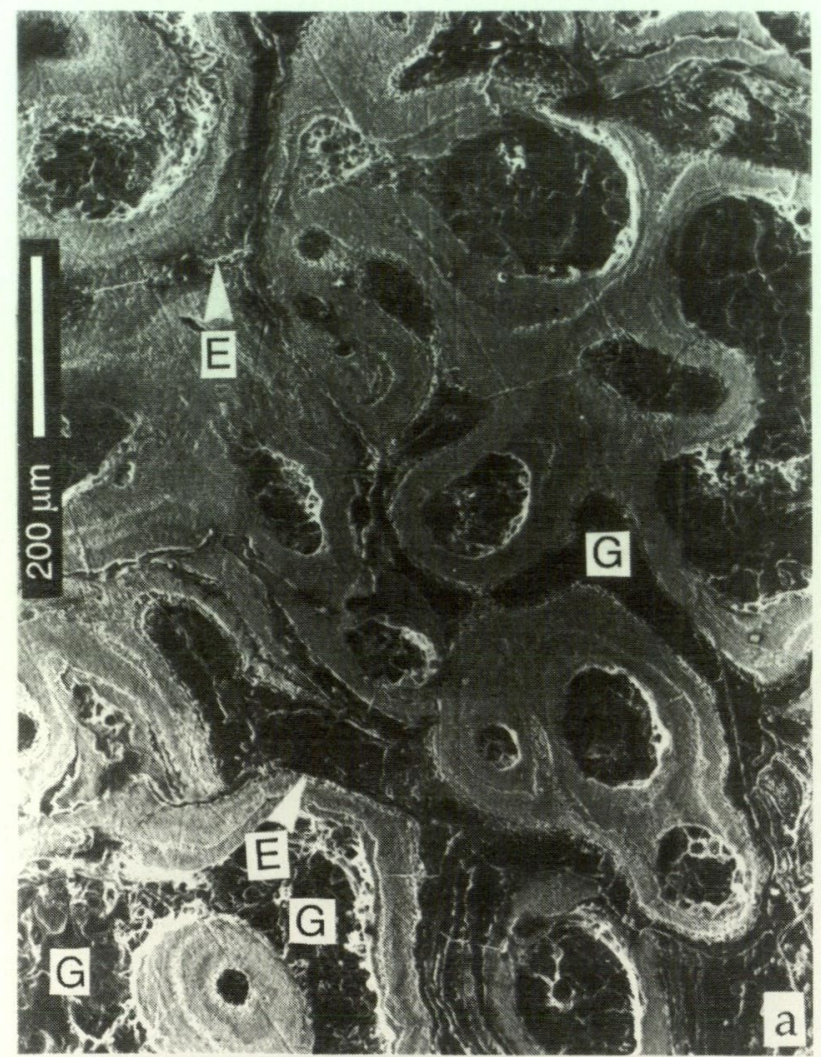

of that group available. The Australian specimens of Dipnorhynchus are heavily modified by boring and perhaps slight recrystallisation. On one specimen of D. sussmilchi, ANU 18815, a small patch of palatal dentine shows dentine tubules arising from the thin vascular columns. Campbell and Barwick $(1999,2000)$ have illustrated some of the tissue which seemingly is without dentine tubules.

In much current terminology, the presence of dentine tubules is regarded as an obligatory character of dentine, but this is not correct. Naturally in this investigation we were interested in discovering if dentine was present, and for this reason the discovery of dentine tubules was an objective. Nowhere in any section examined by SEM or by optical sections were such tubules found (Figures 6-12). In the absence of tubules, dentine can be distinguished by its position in relation to bone and the depositional surface, by its lack of spaces that could be interpreted as osteocyte spaces, and by the clear crystalline nature of the tissue discussed. In Dipnotuberculus the dark-coloured material lies between the lamellar bone with its osteocyte spaces and the surface of the dental plates, although no enamel has been discovered on the plates. Thus this tissue has the position of dentine, and is crystalline, but it lacks osteocyte spaces and dentine tubules. We therefore refer to it as dentine. Note however that in some sections it contains numbers of open spaces (Figure 11c), that could be interpreted as sections across tubules, but these show no sign of being organised into a linear pattern. This could be the result of the orientation of the section, though this is unlikely. Also the margins of vascular canals show no sign of tubules around them, places where they should appear if they were present, because no infilling had taken place. In our view no dentine tubules are present in Dipnotuberculus.

The dentine lies directly on light coloured bone, and the contact between two tissues is continuous. No sign of a pulp cavity is present. Optical sections expose depressed osteocyte spaces in the bone, which are depressed in vertical section, but are more obvious in horizontal sections. As Figure 9c shows, distinct osteones contain laminar bone in which the osteocyte spaces have been observed. Between adjacent osteones there are lightly mineralised cancellous tissues (Figure 9c), or spaces which are now filled with calcite. In the contact areas where the lateral tuberosities meet the larger median tuberosities (Figure 8b-c), the bone comes close to the buccal surface and spaces within it are

Figure 10 Back Scatter SEM images of two sections of dentine (a). Dentine near the contact between the bone and dentine. Resorbed edges shown (E) and obvious gaps $(G)$ which were originally occupied by soft tissue between the dentine bundles. (b). Near the contact between the bone and the dentine showing calcite filled spaces within the vascular openings and the spaces between the vascular bundles (BV). Gaps and resorbed edges as in (a). Area outlined is reproduced at greater enlargements in Figures 11a,b. 
occupied by sediment which in places continues through the overlying dentine to reach the surface.

Towards the contact with the adjacent dentine, the white bone has darker layers within it, and these are closely similar to the nearby dentine (Figure $9 \mathrm{a}, \mathrm{b})$, and they contain no osteocyte spaces. In some places the laminar bone alternates with the darkcoloured dentine, indicating that a change took place from deposition of bone to dentine more than once. This seems to be a very complex pattern and may be called into question, but we see no other interpretation of our observations. Analysis of the dark layers using the EDAX method on the Cambridge SEM did not show any chemical difference between these layers and the dentine. This suggests that both osteocytes and odontoblasts occurred in the vascular spaces, and the different hard tissues were deposited alternately. As a result of this there is a gradation between bone and dentine over a short vertical distance, but the change is sufficiently rapid to produce a clearly defined boundary to the naked eye.

Sections through the dentine of both the lateral and more median tuberosities are illustrated. The dentine close to the bone contains a number of open spaces now filled with calcite (Figure 10a,b), which represent soft tissue spaces in the original. In addition some large spaces show that they were resorbed from the surrounding dentine, and their edges are reversal lines (Figures $6 b-e ; 12 c, d$ ). Their boundaries cut across the concentric bands of the adjacent tissues. The number of such openings decreases rapidly towards the buccal surface. Some of these openings are irregular in shape, but others are long and narrow, the elongate ones being long sections of vascular canals and show concentric banding around their margins (Figures $6 d ; 12 c, d)$.

We conclude that large resorbed openings were subsequently filled by new dentine deposited around newly formed arborescent pulp canals. In the sense of Campbell and Smith (1987), this infilling dentine is an example of pleromic dentine. In many places, the infillings are lined with extensive bands of dentine which must have been deposited by odontoblast cells lining the inner surface. These layers surround several smaller vascular canals which occupy the main body of the space. There are branches of these canals showing that they were arborescent in their form. Each canal is surrounded by concentric layers of tissue, demonstrating that the layers were deposited in succession around the canals. Ultimately the whole resorpion space was filled with dentine, and many of the smaller vascular canals were almost completely occupied by dentine (Figures 6d,e; 7a,b; 12c,d; 13a,b). In some other areas a single vascular canal occupies a whole resorption space (Figure 13).
Sections through the dentine in the lateral and the large internal tuberosities are illustrated in several figures (Figures 6b,d,e; 9d; 11a,b). The vascular canals in the surface layers are variously oriented, but some are almost at right angles to the surface (Figure $6 \mathrm{~b}, \mathrm{c}$ ). Others have random orientation, and are closely spaced. Towards the base of the dentine near its contact with the underlying bone, they are more widely spaced than near the buccal surface, and the spaces within the columns are largely open. Towards the buccal surface they are densely packed, have small open spaces within the columns, and the columns are packed one on the other.

The dentine has been examined in optical thin sections and by SEM examination of sections cut parallel with the optical section. The layers of tissue are continuous and indicate that they were laid down in columns around the vascular canals. Obviously, as the soft tissue retreated down the canals during growth, it left behind the successive layers of tissue. So the next question is what causes the light and dark banding? EDAX shows that there is no difference in chemistry between the layers. However, enlargement by SEM shows that the layers have different crystal patterns. Some layers have crystals in bundles in a variety of orientations in relation to the boundary of the layers, alternating with layers of randomly oriented crystals some crystals oriented normal to others (Figures $11 \mathrm{a}-\mathrm{d}$; $13 a, b)$. In most instances the boundaries between the layers are clear, but elsewhere there is a gradation. In some places it is possible to recognise separate layers within a single coloured band of tissue (Figure 11b). This implies periodic deposition of a single layer. No evidence of osteocytes is found anywhere in this hard tissue.

The pattern we have described produces a structure described by Ørvig (1951: 335) as dentinal osteons. Orvig goes on to comment that the lamellae contain delicate fibres which alter their directions somewhat from one lamella to the next'. Assuming that the orientation of the cells controls the orientation of the crystals, such an observation would provide an explanation of the data given above. However because the overall structure is complicated into multiple groups of vascular canals, the structure in Dipnotuberculus is more complex than this. The hardness of the buccal surface was probably increased by the alternating layers of crystal bundles.

\section{GROWTH OF THE DENTAL SURFACES}

No growth series of the dental plates is available, but it is possible to give some indication of how the plates grew.

1. There is no enamel on the surface of the plates as they are preserved, and the dentine in the structure is different from that of any dipnoan 

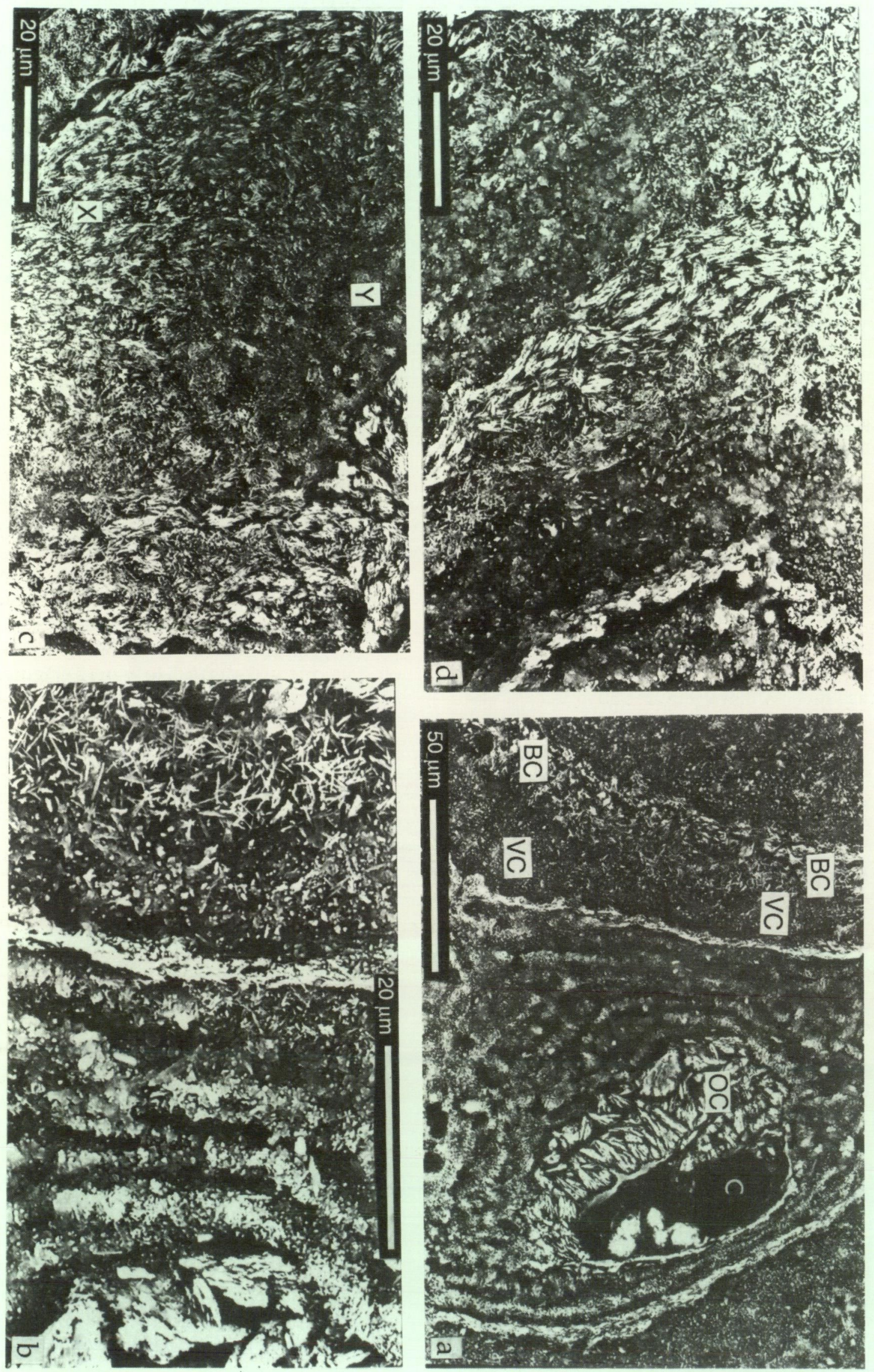
such as the extant species, as well as any Late Devonian or Carboniferous species.

2. The growth of the lateral tubercles and of the surfaces of the tissue inside them implies that the growth during the later ontogeny took place by the addition to the base of the plate which permits the thickness and the lateral extension of the elements to occur. The palatal material thins out at certain points and the underlying bone becomes close to the buccal surface laterally, allowing extension to occur. This allows the dentine of the plate to replace bone laterally as well as vertically, although the vertical growth is at a greater rate than the lateral growth to maintain the rounded structure on the features of the buccal surface. For this process to take place, there is obviously no need to have a space at the base of the dentine, but rather larger canals in the base of the dentine, which are progressively filled up with new tissue.

3. Another method of adding to the margins of the tooth plates is by the addition of blisters on the sides of the plate. Similar features occur in Dipnorhynchus and Chirodipterus australis. In this new species the bone of the prearticular and the pterygoid grew laterally into the spaces between the blisters and joined them together.

4. The growth of dentine at its base must require a change in the material deposited. This does not result from the replacement of prearticular or the pterygoid bone, but by a change in the material deposited in the vascular spaces to form complete layers of new material. This produces the dense mass of dentine in the plate. Because the growth of the plate continued through the ontogeny of the animal, one would expect to find some lighter coloured layers in the tissue towards the buccal surface resulting from deposition when the animal was young.

5. Finally, the spaces into which the tuberosities of the palate fit into the prearticulars, show a coarse texture resulting from the intergrowth of the basal bone and the dentine. As indicated above, this allows differential growth to take place.

The lateral tuberosities were present early in the growth of the animal, and were added to vertically by growth into the basal bone and laterally into the open labial space. Their inner edges are moved laterally as new material is added at their inner margins. Growth of bone took place in the furrows causing extension of the plate laterally, but not producing any obvious sutures. This is shown on Figure $8 \mathrm{~b}, \mathrm{c}$. The structure of the palate is not so clear as we had hoped, and we are unable to cut it for thin sections. However, there are features that support the view developed from the mandible. The tuberosities are large and smooth surfaced, indicating that they have continuous accretion of dentine and bone beneath them. The furrows in between are much rougher on the buccal surface, indicating that they are made of a mixture of hard dark bone and pterygoid bone. Thus the bone must be close up under the buccal surface, a feature which we would expect if our mandibular interpretation is correct.

With regard to the palate, no median suture is present, so that the growth of the plate had to take place along the lateral and posterior margins. In dentine plated forms the median edge is a zone of active modification as the tissue was eroded and added to periodically. This also means that there would be no addition of tissue to the lateral margins of the parasphenoid. That bone could increase only by addition to its posterior and posterolateral edges. Where the anterior edge of the bone lay is quite unknown. In later dipnoans, the buccohypophyseal opening is near the anterior end of the parasphenoid. As a result, we would expect the edge to be in about that position on our current specimens. In the light of what we have written about the addition of tissue to the palatal surface, care has to be taken about the use of furrows in the surface to define the boundary of the bone. We also note that the absence of a buccohypophyseal foramen in one specimen may be the result of deposition of the tissue of the dental plates over its surface in later life.

In the mandible, the dental plates also have a number of replacement patches low on the lingual surface and apparently made of the same material as the dental plates themselves. We suspect that it forms a means of modification of the inner edge of

Figure 11 Landscape image of back scatter SEM images of the dentine making up the large tuberosities. Buccal surfaces to the left side of the Figure. (a) An asymmetrical section, being an enlargement of Fig. $10 \mathrm{~b}$. Bundles of crystals against the vascular canal (C) followed outwards by layers of organised crystal bundles alternating with irregularly arranged fine crystals. Larger layer of organised crystals (OC) and then wider bands of crystals at right angles to the surface (VC) and a layer of bundled crystals (BC). (b) An enlargement of part of (a). Note that in the banded section on the right of the image most of the crystals stand with their axes at a high angle to the surface, but the orientation of the crystals in the dark bands is not known. (c-d) Two further views of the several layers showing crystal orientation. Note in (c) that the character of a single layer of crystals may change along the length of a layer from $X$ where the crystals have their long axes parallel with the plate surface, to $Y$ where most of the crystals have their long axes normal to the plate surface. 

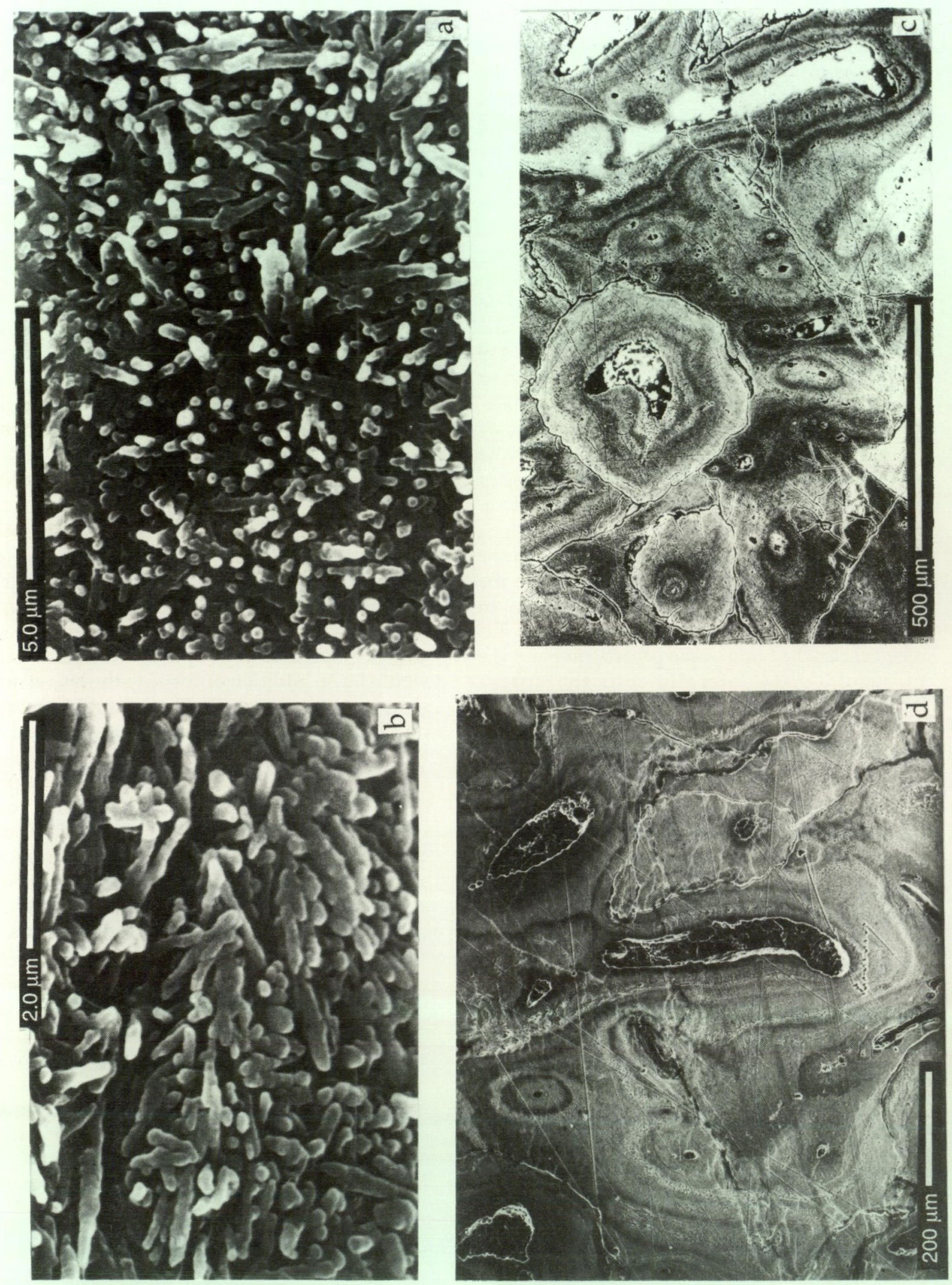

Figure 12 Landscape image with the buccal surface towards the left side of the Figure. (a). back scatter SEM image showing most crystals on the left with axes normal to the page, and more elongate crystals on the right. (b). a greater enlargement showing randomly oriented crystals. (c-d). In (c) the vascular canal in the centre and the one on the left have reversal edges around them transecting the dentine layers in the surrounding material. Note the small dark spots which represent almost completely filled branches of the vascular canals. On the right side of the Figure note the elongate vascular cavity with the concentric layers of tissue surrounding it. Elsewhere on the Figure note the small formerly vascular spaces now almost completely filled with layered tissue. (d). Similar view to (c) with layers of tissue surrounding several vascular canals. Interpretation of both (c and d) given on Figure 13. 

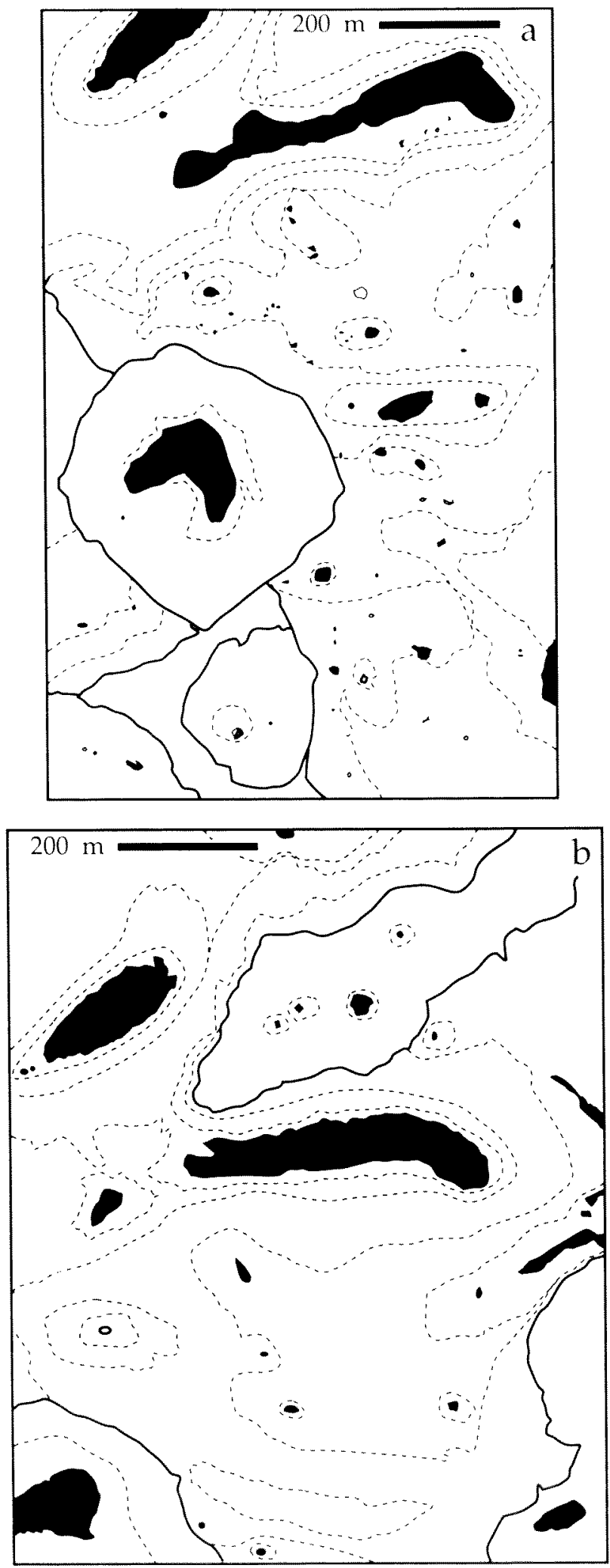

Figure 13 Drawings of Figures $12 \mathrm{c}-\mathrm{d}$ showing the layers of dentine, the margins of resorption spaces into which new dentine grew, and the vascular bundles in black. Some small vascular bundles have been filled with dentine. Some of the layered bands are shown by dotted lines, their position indicating the shapes of the layers and their transgression by thick black reversal lines. the tooth plate during the development of the mandibular dental plates. The same kind of structure is found in C. australis, but it is not present in Dipnorhynchus. In that genus the whole structure is found to be covered in the internal face of the mandible with small denticles of approximately even size, which we interpret to be an initial variety of such denticles (Campbell and Barwick 2000, Figure 10D).

\section{RELATIONSHIPS}

At first sight, this genus is very reminiscent of Dipnorhynchus sussmilchi and D. kurikae. The external surface, where preserved, is cosmine covered, the median length in the mandible is high, the dental plates are made mainly of bone and thickened dentine on the buccal surface, the posteromedial edge of the prearticulars is formed of a well rounded tuberosity based on bone, the anterior furrow is well developed, the adductor fossa is large and the palate is large and is completely lacking in real teeth. In particular, the structure of the dental plates is very different from any dipnoan apart from the dipnorhynchids. Only the primitive dipnorhynchids have plates in which, at the lateral margins of the plate, the gross form is altered by addition of new material differentially to the contact between the dental plate and the underlying bone. This produces a dental structure that is thick and made of complex material. The lateral margins of the dental plates grow by the addition to the margins of small projections made of the same material as the plates themselves. For this reason alone we consider that Dipnotuberculus must be placed in the Dipnorhynchina

On closer inspection, some differences from other members of the Dipnorhynchina are apparent. These are:

1. no dermopalatine plates are fused into the palate;

2. the braincase walls are not fused to the top of the palate;

3. the posterior wall of the skull is not heavily ossified;

4. the median-posterior end of the dental plates on the prearticulars stop well short of the posterior end of the mandible;

5. the lateral marginal ridges on the prearticular plates are absent or poorly developed;

6. the anterior furrow is open posteriorly;

7. the hard tissue of the pterygoids is not so strongly ossified, and where the surface has been eroded away, coarsely tubercular bone is widely exposed;

8. there are no thick ridges in the adductor chamber of the mandible for the attachment of adductor muscles;

9. no large process is present on the dorsal palate; 
10. the preorbital/postnasal process was not ossified, but was probably formed of cartilage.

As (Westoll 1949) showed, the evolutionary history of Palaeozoic dipnoans shows many features in common across the whole range of genera. Many of these features were outlined in tabular form by Westoll, and among the skull and mandible characters he listed 17 features that changed. Some of these features associated with the dermal bones of the skull, are not preserved on the Moroccan material, but others are well preserved. Taking into account the discoveries of Westoll and the new information which has been developed in the subsequent 50 years, we note that items 1, 3, 4, $6,8,9$ and 10 , are features that occur in a variety of dipnoans. In this sense such features are of little value in estimating relationships, and if these were fed into a database they would dominate the features we consider to be fundamental to the analysis of the material. The structure of the dental plates alone allows us to signify its position without reference to a cladistic analysis. We have not done such analysis, for the reasons given above, and we regard this new species as being a member of one of the three basic types of dipnoans recognised by Campbell and Barwick (1990).

Dipnotuberculus is regarded as a development of the basic type represented by Dipnorhynchus. Should this be so, it is clear that the group of dipnorhynchids split up into the chirodipterid and Moroccan types prior to the late Middle Devonian. This is not surprising, as the method of breaking down food by radial tooth plates is probably much more efficient that the large tubercles observed in dipnorhynchids. In fact, radial tooth rows developed from bony dipnorhynchid plates as shown by Speonesydrion, and radial patterns also appear in other groups of organisms which used their palates for biting. Examples are the holocephalans and some sharks. The radially arranged tooth rows with new material added at the ends of each row, provides a basis for rapid change in dental patterns and also for easy modification of wear.

Another point which supports the dipnorhynchid interpretation is the absence of a separate parasphenoid on the buccal surface in this new form. Campbell and Barwick (1985, 2000) have shown that in Dipnorhynchus, no separate parasphenoid is present on the buccal surface between the posterior end of the pterygoids, and other specimens of the same genus have confirmed this interpretation. Some specimens of $D$. kurikae show a possible edge on the parasphenoid on the dorsal surface of the palate where the braincase has been removed during preservation, but this shows the edge of the parasphenoid as lying just in front of the buccohyphophyseal canal. In another member of the oldest group,
Sorbitorhynchus, a suture has developed between the pterygoids and a clear parasphenoid is present. We note that in Dipnotuberculus no sign of any breaks appear on the broken surface across the palate, and in this respect it is more like Dipnorhynchus. The dorsal opening for the buccohypophyseal canal is present on a ridge as normally occurs in Dipnorhynchus and in Uranolophus, but no evidence of such a break occurs in its vicinity. We conclude that the buccal surface of the palate was a single structure without any sign of a median or parasphenoidal sutures. The dorsal surface of Dipnotuberculus available to us is too poorly preserved to determine if any parasphenoidal boundary is present as in $D$. kurikae. So far as we are aware, this arrangement of the parasphenoid in ventral and dorsal views, occurs only in dipnorhynchids.

\section{ACKNOWLEDGEMENTS}

Apart from the acknowledgements set out in the Introduction, we wish to acknowledge the assistance of the following people and organisations.

The Natural Sciences and Engineering Research Council of Canada provided the funds for Chatterton's work in Morocco. Ms Susan Stevenson for her photographic work on the broken specimen in the National Museum of Scotland. Professor Moya Smith for a discussion of the dentine and for permission to read an unpublished summary of the current state of play in dentine nomenclature. She has also read the paper and offered comments on its interpretation of the dental plate structure. She does not agree with some of our interpretations. Dr Hervé Lelièvre for the use of the photographs of the specimen from the National Museum of Scotland before it was broken (Figure $2 \mathrm{a}-\mathrm{b}$ ). The cooperation of Brian Eberhardie in locating the mandible now in the University of Alberta Collection and making it available to Chatterton. At the Geology Department, Australian National University, sections for optical analysis and SEM examination were prepared by John Vickers and John Seeley. SEM examination was done by Dr Roger Heady. Dr Robert Nichol dissolved material from one of the specimens for conodont analysis. Prof. Tony Eggleton examined the specimens of apatite to determine their wear on abrasion.

\section{REFERENCES}

Bensaid, M.P., Bultynck, P., Sartenaer, P., Walliser O.H. and Ziegler, W. (1985). The Givetian-Frasnian boundary in pre-Sahara Morocco. In Ziegler, W. \& Werner, R. (eds) Devonian series boundaries - results of world-wide studies. Courier Forshungsinstitut Senkenberg 75: 287-300. 
Berg, L.S. (1940). Classification of fishes both Recent and Fossil. Trudy Zoologia Institut Leningrad 5: 1-517.

Bultynck, P. (1985). Lower Devonian (Emsian) - Middle Devonian (Eifelian and lowermost Givetian) conodont successions from the Ma'der and the Tafilalt, southern Morocco. In Ziegler, W. \& Werner, R. (eds) Devonian series boundaries - results of worldwide studies. Courier Forschungsinstitut Senkenberg 75: 261-265.

Campbell, K.S.W. and Barwick, R.E. (1985). An advanced dipnorhynchid lungfish from the Early Devonian of New South Wales, Australia. Records of the Australian Museum 37: 301-316.

Campbell, K.S.W. and Barwick, R.E. (1990). Palaeozoic dipnoan phylogeny: functional complexes and evolution without parsimony. Paleobiology 16 (2): 143169.

Campbell, K.S.W. and Barwick, R.E. (1999). A new species of Devonian lungfish Dipnorhynchus from Wee Jasper. Records of the Australian Museum 51: 123140.

Campbell, K.S.W. and Barwick, R.E. (2000). The braincase, mandible and dental structures of the Early Devonian lungfish Dipnorhynchus kurikae from Wee Jasper, New South Wales. Records of the Australian Museum 52: 1-26.

Campbell, K.S.W., Barwick, R.E. and Lindley, I.D. (2000). New data on the early Devonian lungfish, Dipnorhynchus. Alcheringa 24: 277-298.

Campbell, K.S W. and Smith, M.M. (1987). The Devonian dipnoan Holodipterus: dental form variation and remodelling growth mechanisms. Records of the Australian Museum 39: 131-167.

Hollard, H. (1974). Recherches sur la stratigraphie des formations du Devonian Moyen, de l'Emsian superieur au Frasnien dans le sud du Tafilalt et dans le Ma'der (Anti-Atlas oriental). Notes $d u$ service Géologique du Maroc 36: 7-68.

Krupina, N.I, and Reisz, R.R. (1999). Reconstruction of the dentition of the hatchlings of Andreyevichthys epitomus, a Late Famennian dipnoan from Russia. Modern Geologie 24: 99-108.

Lelièvre, H. (1995). Description of Maideria falipoui n.g. n.sp., a long snouted brachythoracid (Vertebrata, Placodermi, Arthrodira) from the Givetian of Maider (South Morocco) with a phylogenetic analysis of primitive brachythoracids. Bulletin du Muséum Nationale Histoire Naturelle, 4th Series, 17: 163-207.

Ørvig,T. (1951). Histological studies of placoderms and fossil elasmobranchs.1. The endoskeleton, with remarks on the hard tissues of lower vertebrates in general. Arkiv Zoologica, 2: 321-454.

Smith, M.M. and Campbell K.S.W. (1987). Comparative morphology, histology and growth of the dental plates in the Devonian dipnoan Chirodipterus. Philosophical Transactions of the Royal Society of London, B, 317: 329-363.

Thomson, K. S. and Campbell, K.S.W. (1971). Structure and relationships of the primitive Devonian lungfish Dipnorhynchus sussmilchi (Etheridge). Bulletin of the Peabody Museum of Natural History 38: 1-109.

Westoll, T.S. (1949). On the evolution of the Dipnoi. In Jepsen, G.L. Mayr, E. and Simpson, G.G. (eds) Genetics, Paleontology and Evolution. 121-184. Princeton University Press.

Manuscript received 28 May 2001; accepted 9 October 2001. 